Cochrane Database of Systematic Reviews

\title{
Stent placement versus surgical palliation for adults with malignant gastric outlet obstruction (Review)
}

Upchurch E, Ragusa M, Cirocchi R

Upchurch E, Ragusa M, Cirocchi R.

Stent placement versus surgical palliation for adults with malignant gastric outlet obstruction.

Cochrane Database of Systematic Reviews 2018, Issue 5. Art. No.: CD012506.

DOI: 10.1002/14651858.CD012506.pub2.

www.cochranelibrary.com 
TABLE OF CONTENTS

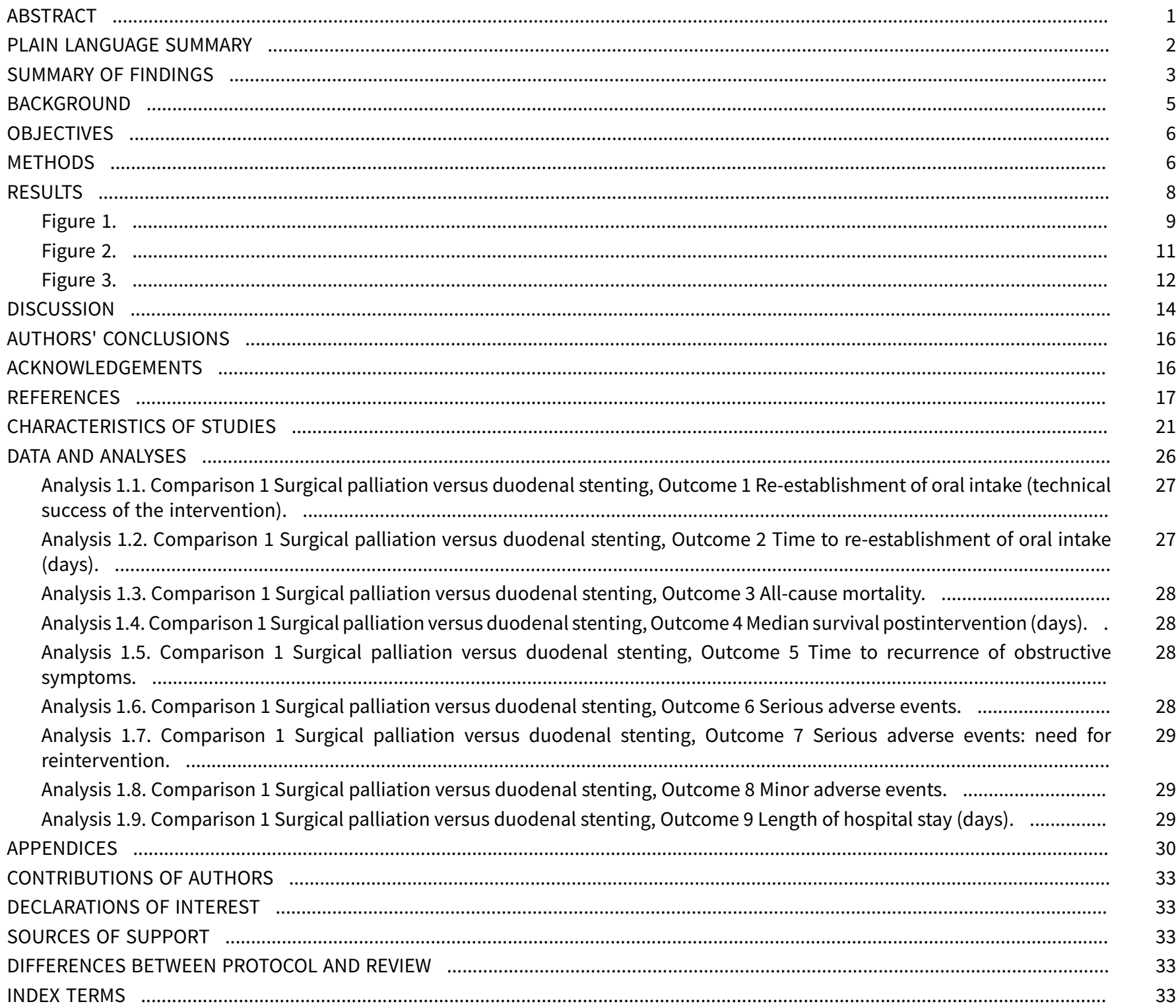


[Intervention Review]

\section{Stent placement versus surgical palliation for adults with malignant gastric outlet obstruction}

Emma Upchurch ${ }^{1}$, Mark Ragusa ${ }^{2}$, Roberto Cirocchi ${ }^{3}$

1Department of Colorectal and Upper Gastrointestinal Surgery, Gloucestershire Hospitals NHS Foundation Trust, Cheltenham, UK.

2Perugia University Medical School, Terni, Italy. ${ }^{3}$ Department of General Surgery, University of Perugia, Terni, Italy

Contact: Emma Upchurch, Department of Colorectal and Upper Gastrointestinal Surgery, Gloucestershire Hospitals NHS Foundation Trust, Sandford Road, Cheltenham, Gloucestershire, GL537AN, UK.em_upchurch@hotmail.com, emma.upchurch@glos.nhs.uk.

Editorial group: Cochrane Upper $\mathrm{Gl}$ and Pancreatic Diseases Group.

Publication status and date: New, published in Issue 5, 2018.

Citation: Upchurch E, Ragusa M, Cirocchi R. Stent placement versus surgical palliation for adults with malignant gastric outlet obstruction. Cochrane Database of Systematic Reviews 2018, Issue 5. Art. No.: CD012506. DOI: 10.1002/14651858.CD012506.pub2.

Copyright (c 2018 The Cochrane Collaboration. Published by John Wiley \& Sons, Ltd.

\section{A B S T R A C T}

\section{Background}

Malignant gastric outlet obstruction is the clinical and pathological consequence of cancerous disease causing a mechanical obstruction to gastric emptying. It usually occurs when malignancy is at an advanced stage; therefore, people have a limited life expectancy. It is of paramount importance to restore oral intake to improve quality of life for the person in a manner that has a minimal risk of complications and a short recovery period.

\section{Objectives}

To assess the benefits and harms of endoscopic stent placement versus surgical palliation for people with symptomatic malignant gastric outlet obstruction.

\section{Search methods}

In May 2018 we searched the Cochrane Central Register of Controlled Trials, Ovid MEDLINE, Ovid Embase and Ovid CINAHL. We screened reference lists from included studies and review articles.

\section{Selection criteria}

We included randomised controlled trials comparing stent placement with surgical palliation for people with gastric outlet obstruction secondary to malignant disease.

\section{Data collection and analysis}

Two review authors independently extracted study data. We calculated the risk ratio (RR) with 95\% confidence intervals (CI) for binary outcomes, mean difference (MD) or standardised mean difference (SMD) with $95 \% \mathrm{CI}$ for continuous outcomes and the hazard ratio (HR) for time-to-event outcomes. We performed meta-analyses where meaningful. We assessed the quality of evidence using GRADE criteria.

\section{Main results}

We identified three randomised controlled trials with 84 participants. Forty-one participants underwent surgical palliation and 43 participants underwent duodenal stent placement. There may have been little or no difference in the technical success of the procedure (RR $0.98,95 \% \mathrm{Cl} 0.88$ to 1.09 ; low-quality evidence), or whether the time to resumption of oral intake was quicker for participants who had undergone duodenal stent placement (MD -3.07 days, $95 \% \mathrm{Cl}-4.76$ to -1.39 ; low-quality evidence). 
Due to very low-quality evidence, we were uncertain whether surgical palliation improved all-cause mortality and median survival postintervention.

The time to recurrence of obstructive symptoms may have increased slightly following duodenal stenting (RR 5.08, $95 \% \mathrm{Cl} 0.96$ to 26.74 ; moderate-quality evidence).

Due to very low-quality evidence, we were uncertain whether surgical palliation improved serious and minor adverse events. The heterogeneity for adverse events was moderately high (serious adverse events: $\mathrm{Chi}^{2}=1.71$; minor adverse events: $\mathrm{Chi}^{2}=3.08$ ), reflecting the differences in definitions used and therefore, may have impacted the outcomes. The need for reintervention may have increased following duodenal stenting (RR 4.71, $95 \% \mathrm{Cl} 1.36$ to 16.30 ; very low-quality evidence).

The length of hospital stay may have been shorter (by approximately 4 to 10 days) following stenting (MD -6.70 days, $95 \%$ Cl -9.41 to -3.98 ; moderate-quality evidence).

\section{Authors' conclusions}

The use of duodenal stent placement in malignant gastric outlet obstruction has the benefits of a quicker resumption of oral intake and a reduced inpatient hospital stay; however, this is balanced by an increase in the recurrence of symptoms and the need for further intervention.

It is impossible to draw further conclusions on these and the other measured outcomes, primarily due to the low number of eligible studies and small number of participants which resulted in low-quality evidence. It was not possible to analyse the impact on quality of life each intervention had for these participants.

\section{PLAIN LANGUAGE SUMMARY}

\section{Stent placement versus surgery to control symptoms of a blocked stomach outlet caused by inoperable cancer}

\section{Review question}

Is surgery or an endoscopic stent better for the treatment of blockage of the stomach (gastric) outlet that is caused by cancer?

\section{Background}

Cancers of the upper gastrointestinal tract (stomach, small bowel, pancreas) can block the outlet of the stomach leading to vomiting, abdominal pain and the inability to eat or drink. For people whose survival is already limited by their cancer, these symptoms are distressing and will ultimately shorten their life expectancy. Restoring the ability to eat and drink is of supreme importance to improve their quality of life.

Two interventions are available to overcome this blockage. A surgical procedure to join the stomach to the upper small bowel (gastrojejunostomy), thereby, diverting food around the blockage can be performed. This can be done via an incision in the abdomen (open) or via small keyhole incisions (laparoscopic). The alternative is the placement of a plastic or metal tube (stent) across the narrowed or blocked area which is placed through the mouth and oesophagus (food pipe) (endoscopic).

\section{Study characteristics}

Three studies with 84 participants compared a surgical operation to bypass the blockage with the placement of a duodenal stent to bridge the blockage. The evidence is current to May 2018.

\section{Key results}

All studies found that people were able to eat and drink sooner following the placement of a duodenal stent and were subsequently discharged from hospital quicker. The return of symptoms was more likely after a stent and people required further treatment to again restore the ability to eat and drink.

There was a higher number of immediate problems in the participants undergoing gastrojejunostomy, including wound and chest infections. In some of the participants who had a stent, subsequent blockage of the stent occurred that required a repeat procedure.

\section{Quality of the evidence}

The studies included only a small number of participants and all studies were used slightly different methods, making it difficult to be certain of the key results. 


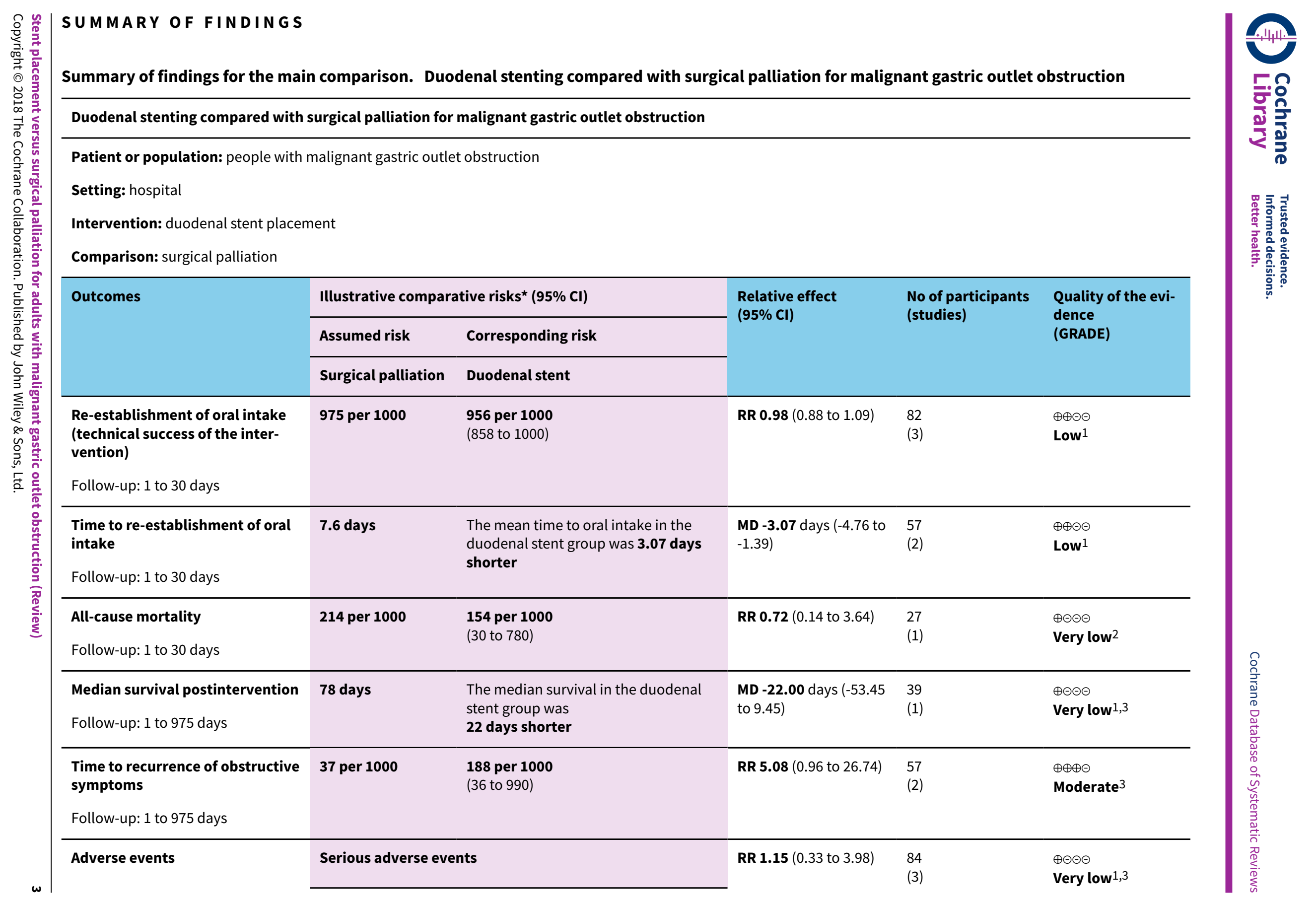




\begin{tabular}{|c|c|c|c|c|}
\hline 98 per 1000 & $\begin{array}{l}\mathbf{1 1 2} \text { per } 1000 \\
\text { (32 to } 388)\end{array}$ & & & \\
\hline \multicolumn{2}{|c|}{ Serious adverse events (need for reintervention) } & \multirow[t]{2}{*}{ RR 4.71 (1.36 to 16.30$)$} & \multirow{2}{*}{$\begin{array}{l}84 \\
(3)\end{array}$} & \multirow{2}{*}{$\begin{array}{l}\oplus \ominus \odot \odot \\
\text { Very low } 3,4\end{array}$} \\
\hline 49 per 1000 & $\begin{array}{l}230 \text { per } 1000 \\
\text { (66 to } 795)\end{array}$ & & & \\
\hline \multicolumn{2}{|c|}{ Minor adverse events } & \multirow[t]{2}{*}{ RR 0.35 (0.07 to 1.61$)$} & \multirow{2}{*}{$\begin{array}{l}84 \\
(3)\end{array}$} & \multirow{2}{*}{$\begin{array}{l}\oplus \ominus \ominus \ominus \\
\text { Very low } 1,5\end{array}$} \\
\hline 341 per 1000 & $\begin{array}{l}120 \text { per } 1000 \\
\text { ( } 24 \text { to } 550)\end{array}$ & & & \\
\hline 12.9 days & $\begin{array}{l}\text { The mean length of hospital stay in the } \\
\text { duodenal stent group was } \mathbf{6 . 7 0} \text { days } \\
\text { shorter }\end{array}$ & $\begin{array}{l}\text { MD -6.70 days ( } 9.41 \\
\text { lower to } 3.98 \text { lower) }\end{array}$ & $\begin{array}{l}84 \\
(3)\end{array}$ & $\begin{array}{l}\oplus \oplus \oplus \ominus \\
\text { Moderate }^{3}\end{array}$ \\
\hline
\end{tabular}

Health-related quality of life

*The basis for the assumed risk (e.g. the median control group risk across studies) is provided in footnotes. The corresponding risk (and its $95 \%$ confidence interval) is based on the assumed risk in the comparison group and the relative effect of the intervention (and its $95 \% \mathrm{Cl}$ ).

Cl: confidence interval; MD: mean difference; RR: risk ratio.

GRADE Working Group grades of evidence

High-quality: further research is very unlikely to change our confidence in the estimate of effect.

Moderate-quality: further research is likely to have an important impact on our confidence in the estimate of effect and may change the estimate.

Low-quality: further research is very likely to have an important impact on our confidence in the estimate of effect and is likely to change the estimate.

Very low-quality: we are very uncertain about the estimate.

1Unclear or high risk bias within the studies (very serious concerns) (downgraded by two levels).

2 Unclear or high risk of bias within the studies (downgraded by two levels) in addition to very serious inconsistencies between the studies (downgraded by two levels).

${ }^{3}$ Some imprecision in the results as exemplified by the large confidence intervals (downgraded by one level).

${ }^{4}$ Confidence intervals were wide (overlapped no effect and clinically significant effect) and the sample size was small (downgraded by two levels).

5 Serious inconsistencies between the studies (downgraded by one level). 


\section{B A C K G R O U N D}

See Appendix 1 for a glossary of terms.

\section{Description of the condition}

Gastric outlet obstruction (GOO) is the clinical and pathological consequence of a disease process, which results in a mechanical obstruction to gastric emptying at the distal end of the stomach. It is the result of a variety of pathological processes that culminate in compression and subsequent blockage of the gastric outlet (the area of the stomach by which food exits and enters the small bowel). The causes are typically divided into those resulting from benign (i.e. non-cancerous) disease and those resulting from malignant (i.e. cancerous) disease. The incidence of GOO from benign disease, predominantly peptic ulcer disease, has declined substantially since the identification of Helicobacter pylori and the use of proton pump inhibitors, as this has diminished the incidence of peptic ulcers and consequently their complications (Shone 1995).

Malignant disease now accounts for $50 \%$ to $80 \%$ of cases of GOO, although the exact incidence is unclear (Chowdhury 1996; Johnson 1990; Johnson 1995; Shone 1995). This is likely due to the wide range of cancers that can result in GOO, which leads to difficulties in recording incidence. In addition, the development of this condition is often a near-terminal or terminal event; therefore, this complication may not be documented, leading to difficulties in accurately predicting the number of people affected.

The most common malignancy that results in $\mathrm{GOO}$ is pancreatic cancer, with $15 \%$ to $20 \%$ of people presenting with GOO (Tendler 2002). In 2013, there were 9408 new cases of pancreatic cancer and thus, approximately 1400 to 1900 cases of GOO present in this cohort each year. The obstruction is typically the result of disease extension to the duodenum or stomach, or external compression at the level of the gastric outlet, reflecting the anatomical position of the pancreas in relation to the stomach. A significant proportion of these people also have biliary obstruction.

Distal gastric and more rarely duodenal cancers result in intraluminal obstruction. Although this is typically a late complication, it may be the presenting symptom in these people. Rarer malignancies, including ampullary carcinoma and cholangiocarcinomas, can result in this condition due to their anatomical position. Lymphoma and metastatic disease, if affecting the lymph nodes and structures surrounding the gastric outlet, can also be the cause.

GOO typically presents with progressive symptoms. Vomiting is the predominant feature and this may initially follow solid food intake before ultimately progressing to vomiting following liquid intake. Over time, significant weight loss occurs as a result of both reduced calorie intake and the disease process itself. Thus, the majority of people presenting with $\mathrm{GOO}$ are frail with poor physiological reserve. In addition, continual vomiting can be extremely distressing.

The median survival in this participant cohort may be as short as three to four months, although this depends on the exact tissue type of cancer, volume of metastatic disease and participant comorbidities (Jeurnick 2007a; Lopera 2004). Without intervention, the absence of nutritional intake alongside the electrolyte imbalance that occurs as a result of continual vomiting would be a terminal event for the participant. Due to the short timeframe, the ideal procedure that would alleviate these symptoms would restore oral intake swiftly with minimal complications.

Given the high proportion of people who go on to develop GOO, the role of prophylactic gastrojejunostomy, prior to the development of symptoms, must be considered. Despite extensive preoperative imaging, a proportion of people are found to have unresectable disease at laparotomy. In this group, a gastric bypass, with or without biliary bypass, significantly reduces the incidence of GOO developing (Gurusamy 2013). However, there was no reported evidence of an improvement in quality of life (Gurusamy 2013).

This cohort were undergoing an operation as it was thought that their disease was resectable. There is, at present, very limited evidence evaluating prophylactic gastrojejunostomy in people who are known to have unresectable disease and, thus, not undergoing an exploratory laparotomy. One small, single-centre, randomised study found that a prophylactic gastrojejunostomy effectively prevented symptoms (Miyasaka 2017). Further randomised controlled trials are necessary to establish the impact on quality of life and determine if there is a role for this procedure in people who are known to be unresectable, yet asymptomatic, during staging investigations.

\section{Description of the intervention}

Traditionally, the treatment approach for people with GOO was surgical bypass, consisting of an open gastrojejunostomy. This was first performed in 1881 by Rydygier for a person with a duodenal ulcer (Pach 2008). Later that same year, Wolfer performed a similar operation for a person with pyloric carcinoma that had extended into the pancreas (Robinson 1960).

The operation involves an upper midline incision to gain access to the abdomen. The obstruction is bypassed by forming an anastomosis between the stomach above the level of the obstruction to the small bowel below the level of the obstruction, typically the jejunum. The anastomosis usually takes the form of a Roux-en-y loop, which is an end to side anastomosis, and can be positioned behind or in front of the transverse colon. The anastomosis can either be hand sewn or stapled. To date, there is no evidence favouring either technique.

Developments in minimal access surgery have resulted in the ability to perform this procedure laparoscopically in suitable people. In laparoscopic gastrojejunostomy, the surgical access to the abdominal cavity is via a central port, typically placed just below the umbilicus. The abdominal cavity is distended using carbon dioxide pneumoperitoneum. Further ports, typically three $5 \mathrm{~mm}$ to $10 \mathrm{~mm}$ incisions, are placed for additional instruments. The surgery can be performed entirely laparoscopically with either laparoscopic stitches or, more commonly, with laparoscopic staples used for the anastomosis.

Palliative stent placement for GOO was first reported in the 1990s (Kozarek 1992). Conscious sedation is used and, with the person in the left lateral position, the area of obstruction is reached with an endoscope. A guidewire is passed through the obstruction and with fluoroscopic guidance, a stent is deployed through the working channel of the endoscope to cover the obstruction. Several stents 
are available. They are self-expanding metal stents (SEMS) that can be covered or uncovered depending on whether they are coated. The advantage of covered stents is that they can prevent tumour ingrowth; however, they have a higher rate of stent migration. There is no evidence indicating that either is preferred.

\section{How the intervention might work}

People who develop GOO as a result of their malignancy are usually in the terminal stages of their disease. Therefore, an intervention that alleviates their symptoms and improves their quality of life with minimal recovery time is required.

Surgical palliation is associated with a risk of complications. Complication rates of $25 \%$ to $35 \%$ are reported with a perioperative mortality rate of $2 \%$ (Isla 2000; Johnsson 2004; Lillemoe 1999; Maetani 2005; Mittal 2004). Complications include chest infections, wound infections and anastomotic leak at the site of the bypass. An anastomotic leak can be a devastating complication, resulting in abdominal sepsis and in some cases the need for a second operation.

Laparoscopic surgery may lead to reduced complications, primarily wound complications, and a shorter hospital stay. This has been shown to be the case in other surgical procedures when comparing an open approach to a laparoscopic approach (Bijen 2009; Keus 2006; Reza 2006; Talseth 2014; Walsh 2009).

In addition to the early complications seen in people who have undergone gastrojejunostomy, delayed gastric emptying has been reported to be about 20\% (Watanapa 1992), but as high as 57\% in some studies (Doberneck 1987). For an intervention where restoration of oral intake and quality of life is paramount, this is unquestionably high.

Endoscopic stent placement would reduce the surgical burden placed on the person and reduce the incidence of complications and the length of hospital stay, while producing similar, if not better, improvements in quality of life. However, endoscopic stent replacement is not without its own complications. These include occlusion of the stent from food bolus or tumour ingrowth, resulting in a return of symptoms and the need for another endoscopic procedure. Stent migration can lead to the return of symptoms, necessitating another endoscopic procedure to correct the position. In rare instances, stent migration can lead to perforation of the stomach or small bowel as the stent erodes through the bowel wall.

\section{Why it is important to do this review}

With the avoidance of general anaesthetic and surgical burden of gastrojejunostomy, the potential advantages of endoscopic stent placement for malignant $\mathrm{GOO}$ are desirable. The improvement in symptoms as well as the longevity of any improvement has to be ensured before this method can be widely recommended as the technique of choice. There are current concerns regarding a high rate of late complications caused by stent migration and occlusion, which would preclude its preferential use (Espinel 2001; Lopera 2004). This review aimed to address these concerns and determine if either method produces better results in a cohort of people where timely improvement in symptoms is paramount.

\section{O B JECT IVES}

To assess the benefits and harms of endoscopic stent placement versus surgical palliation for people with symptomatic malignant gastric outlet obstruction.

\section{METHODS}

\section{Criteria for considering studies for this review Types of studies}

Randomised controlled trials (RCTs) of parallel study design eligible for inclusion in this review. The search found no quasi-randomised trials.

\section{Types of participants}

RCTs involving adults (aged 18 years and over) undergoing intervention for $\mathrm{GOO}$, which was considered to be secondary to a malignant process.

\section{Types of interventions}

Studies comparing endoscopic stent placement (including metal stent and SEMS) with surgical palliation (including open, laparoscopic-assisted and laparoscopic gastrojejunostomy). We excluded studies comparing different types of stent.

\section{Types of outcome measures}

\section{Primary outcomes}

1. Measures of the resolution of symptoms.

a. Re-establishment of oral intake (technical success of the intervention).

b. Time to re-establishment of oral intake.

2. All-cause mortality.

a. Short-term mortality (in-hospital mortality, or mortality within three months),

3. Median survival postintervention

\section{Secondary outcomes}

1. Time to recurrence of obstructive symptoms (inability to swallow solids, liquids, or both; epigastric pain on swallowing; postprandial vomiting, or both)

2. Adverse events.

a. Serious adverse events (within three months, including the time point closest to three months). Defined as Clavien-Dindo classification: Grade II or more (Clavien 2009: Dindo 2004).

b. Minor adverse events.

3. Length of hospital stay.

4. Health-related quality of life (using any validated scale).

a. Short term (measured between four weeks and three months).

b. Long term (measured beyond three months).

The choice of the clinical outcomes was based on the necessity of assessing whether stenting or surgical bypass resulted in the quickest resolution of symptoms with the shortest hospital stay. The goal for people with malignant outlet obstruction is quality of life; thus, it is important to understand which method will be more likely to achieve this. 


\section{Search methods for identification of studies}

\section{Electronic searches}

We performed a literature search to identify all published and unpublished RCTs in all languages. We placed no restrictions on the language of publication when searching the electronic databases or reviewing reference lists in identified studies. The search of electronic databases included:

- Cochrane Central Register of Controlled Trials (2017, Issue 2; Appendix 2);

- MEDLINE Ovid (1966 to 7 February 2017; Appendix 3);

- Embase Ovid (1988 to 7 February 2017; Appendix 4); and

- CINAHL (1982 to 7 February 2017).

\section{Searching other resources}

We checked reference lists of all primary studies and review articles for additional references. We searched for errata or retractions from eligible studies on PubMed (www.ncbi.nlm.nih.gov/pubmed).

\section{Grey literature databases}

- Health Management Information Consortium (HMIC) database (www.ovid.com/site/catalog/DataBase/99.jsp).

- National Technical Information Service (NTIS) database (www.ntis.gov/products/ntisdb.aspx).

- OpenGrey (www.opengrey.eu).

- PsycEXTRA (www.apa.org/pubs/databases/psycextra/ index.aspx).

\section{Clinical trials registers and trial result registers}

We searched the following clinical trial registers/trial result registers:

- AstraZeneca Clinical Trials;

- Bristol-Myers Squibb Clinical Trial Registry;

- Clinical Trials.gov;

- Current Controlled Trials metaRegister of Controlled Trials (mRCT):

- active registers (www.controlled-trials.com/mRCT);

- archived registers (www.controlled-trials.com/mrct/ archived);

- Eli Lilly and Company Clinical Trial Registry:

- www.lillytrials.com;

- www.lillytrials.com/initiated/initiated.html;

- EU Clinical Trials Register;

- GlaxoSmithKline Clinical Study Register;

- International Clinical Trials Registry Platform Search Portal;

- International Federation of Pharmaceutical Manufacturers and Associations (IFPMA) Clinical Trials Portal;

- Roche Clinical Trials Results Database.

\section{Data collection and analysis}

\section{Selection of studies}

We included only RCTs. We studied all trials based on cases series or an Institute's own experiences as well as systematic reviews and meta-analyses to avoid any missed RCTs.

\section{Data extraction and management}

Two review authors (EU and $\mathrm{RC}$ ) independently extracted data using a standard data collection form for study characteristics and outcome data, which was piloted on one of the included studies. We extracted the following study characteristics.

- Methods: study design, total duration of study and run in, number of study centres and location, study setting, withdrawals, date of study.

- Participants: number, mean age, age range, gender, primary tumour, tumour stage, histological subtype, performance status, American Society of Anesthesiologists (ASA) status (ASA 2014), inclusion criteria, exclusion criteria.

- Interventions: intervention, comparison, concomitant interventions.

- Outcomes: primary and secondary outcomes specified and collected, time points reported.

- Notes: funding for study, notable conflicts of interest of study authors.

We extracted outcome data from the included studies. Where outcomes were reported multiple times during the same timeframe (e.g. short-term health-related quality of life reported at six weeks and three months), we extracted data for the latter time point (i.e. three months).

\section{Assessment of risk of bias in included studies}

We assessed risk of bias for each study using the criteria outlined in the Cochrane Handbook for Systematic Reviews of Interventions according to the following domains (Higgins 2011):

- random sequence generation;

- allocation concealment;

- blinding of participants and personnel;

- blinding of outcome assessment;

- incomplete outcome data;

- selective outcome reporting;

- other bias.

Each potential source of bias was graded as high, low or unclear, and summarised across studies for each of the domains listed. We acknowledge that blinding of participants and personnel will be impossible, but blinding of outcome assessors was possible and assessed accordingly.

When considering treatment effects, we took into account the risk of bias for the studies that contributed to that outcome as part of the GRADE methodology (GRADEpro GDT). We downgraded a starting rating of 'high-quality' evidence by one level if there were serious concerns and downgraded by two levels if there were very serious concerns. We completed this grading for bias as well as inconsistency between studies, indirectness of the studies in accordance to the review question, imprecision of the results and publication bias in accordance with the GRADEpro GDT criteria.

\section{Assessment of bias in conducting the systematic review}

We conducted the review according to the published protocol and reported any deviations from it in the Differences between protocol and review section. 


\section{Measures of treatment effect}

We analysed dichotomous data (e.g. short-term mortality, proportion of people with serious adverse events) as risk ratios (RR) and continuous data as hazard ratios (HR) where the studies had been analysed with survival techniques (e.g. time to reestablishment of oral intake, time to recurrence of symptoms), as mean differences (MD) when the outcome was reported or converted to the same unit in all the studies (e.g. hospital stay, number of days before returning to work), or as standardised mean differences (SMD) when different scales were used for measuring the same outcome (e.g. quality of life). We reported $95 \%$ confidence intervals $(\mathrm{Cl})$.

We undertook random-effects meta-analyses only where they were meaningful (i.e. if the treatments, participants and the underlying clinical questions were similar enough for pooling to make sense).

\section{Unit of analysis issues}

The unit of analysis was the person undergoing treatment for GOO. We identified no cluster-randomised trials.

\section{Dealing with missing data}

We contacted investigators to verify key study characteristics and obtain missing numerical outcome data as indicated. Where this was unobtainable, we imputed the mean from the median (i.e. considered the median as the mean) and imputed the standard deviation from the standard error, interquartile range or $\mathrm{P}$ values, according to the Cochrane Handbook for Systematic Reviews of Interventions (Higgins 2011). The impact of including such studies is discussed.

\section{Assessment of heterogeneity}

We explored heterogeneity using the $\mathrm{Chi}^{2}$ statistic when required.

\section{Assessment of reporting biases}

We attempted to contact study authors, asking them to provide missing outcome data. Where data had been imputed, we explored the impact of including these studies, where numbers allowed, using a sensitivity analysis.

\section{Data synthesis}

\section{'Summary of findings' table}

We created a 'Summary of findings' table. We used the five GRADE considerations (study limitations, consistency of effect, imprecision, indirectness and publication bias) to assess the quality of the body of evidence based on the studies that contributed data to the meta-analyses for each outcome, classifying it as high, moderate, low or very low.

\section{Subgroup analysis and investigation of heterogeneity}

We planned to carry out the following subgroup analyses.

- Primary malignancy.

- Open versus laparoscopic gastrojejunostomy.

- Anaesthetic risk: ASA I or II (a healthy person or mild systemic disease) versus ASA III or more (a person with severe systemic disease of worse).

Due to the limited number of studies and participants, subgroup analyses were not possible.

\section{Sensitivity analysis}

We planned to perform sensitivity analysis to assess the robustness of our conclusions, involving:

- excluding studies at unclear or high risk of bias (one or more of the risk of bias domains (other than blinding of surgeon) classified as unclear or high);

- excluding studies in which either the mean or standard deviation, or both were imputed;

- excluding cluster RCT in which the adjusted effect estimates were not reported.

Due to the limited number of eligible studies, sensitivity analyses were not possible.

\section{Reaching conclusions}

We based our conclusions on the findings from the quantitative or narrative synthesis of studies included in this review.

\section{RES U LTS}

\section{Description of studies}

The electronic searches identified 535 studies from CENTRAL, Ovid MEDLINE, Ovid Embase and Ovid CINAHL. After removal of duplicates, 425 remained, alongside an additional 34 studies identified through the reference lists. We excluded 420 clearly irrelevant studies through reading the abstract. We assessed 43 references in full text for further assessment, 37 of which were subsequently excluded (Figure 1). 
Figure 1. Study flow diagram.

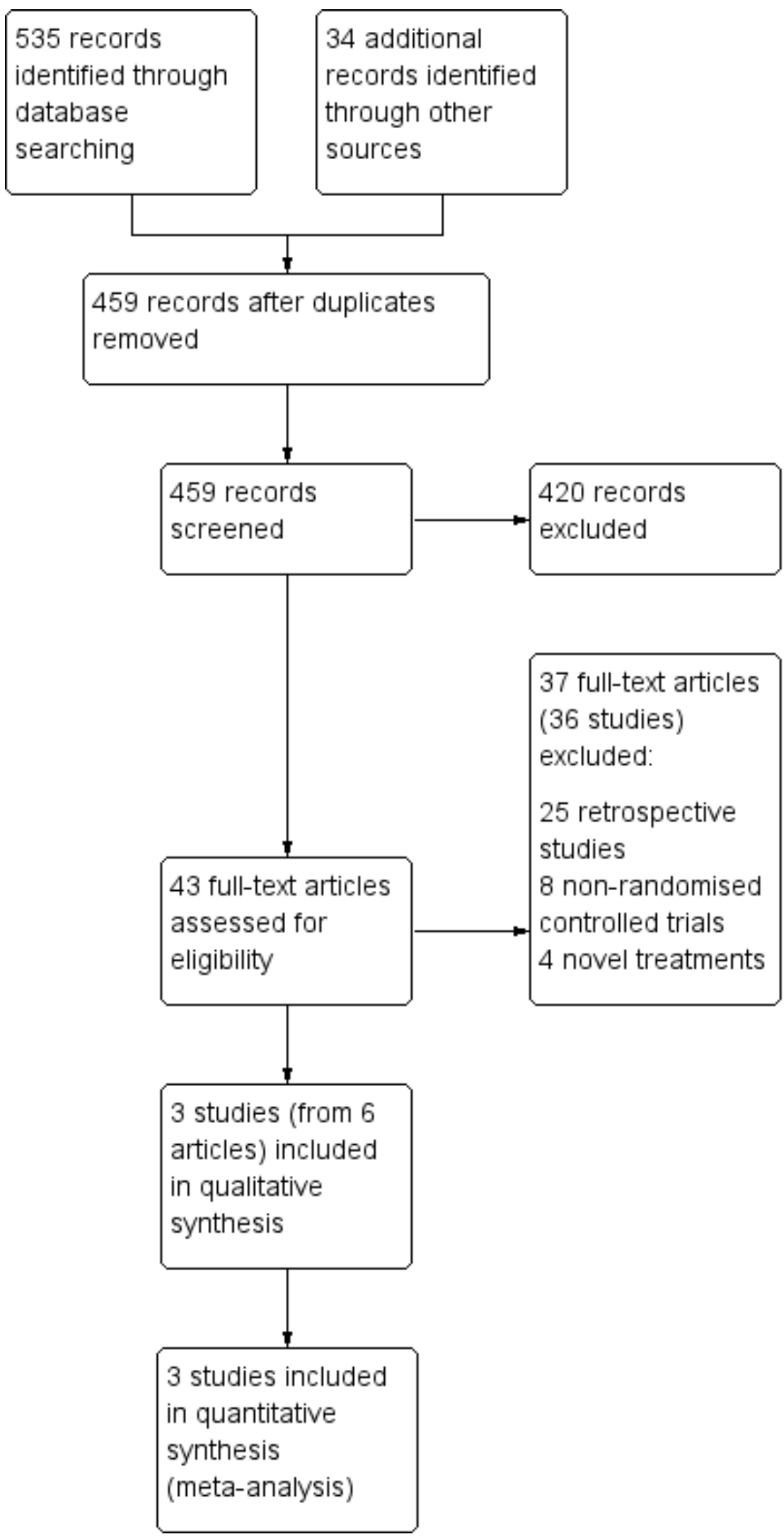




\section{Results of the search}

Three RCTs (four publications) met the inclusion criteria for the review (Fiori 2013; Jeurnick 2010; Mehta 2006). The characteristics of these studies are shown in the Characteristics of included studies table.

\section{Included studies}

All three studies compared duodenal stenting with surgical gastrojejunostomy. Two of the studies compared endoscopic stent placement via the oral route (Fiori 2013; Jeurnick 2010), whereas one study used either an oral (nine participants) or percutaneous gastrostomy tract (three participants) to deploy the duodenal stent (Mehta 2006). Two studies used an enteral Wallstent (Boston Scientific, Natick, MA, USA), which is a non-covered self-expandable metallic stent (Jeurnick 2010; Mehta 2006). The third study used a Ultraflex Covered Stent System (Boston Scientific, Natick, MA, USA), which is a covered self-expandable metallic stent (Fiori 2013).

All studies utilised different surgical techniques. One study performed a laparoscopic gastrojejunostomy with an antecolic jejunal loop and stapled anastomosis (Mehta 2006). Two experienced surgeons who had each undertaken laparoscopic jejunostomy for 10 years and had performed over 50 cases prior to the trial completed the surgical procedures. One study performed an open surgical gastrojejunostomy in all participants with the anastomosis on the posterior wall of the stomach (Fiori 2013). Surgeons with a specialist interest in interventional radiology performed both the surgical gastrojejunostomy and endoscopic stenting. The third study allowed either an open or laparoscopic technique, and either an antecolic or retrocolic jejunal loop (Jeurnick 2010). This multi-centre study did not clarify the experience of and number of surgeons involved. The majority of participants in this study who were randomised to the surgical arm had an open procedure (89\%). The reasons for this were unclear and the numbers were too small for subgroup analysis.

All studies reported on the technical success of the procedure. Two studies reported on the primary outcome of time to reestablishment of oral intake (Fiori 2013; Jeurnick 2010). One of these studies used the GOO scoring system (GOOSS) (Jeurnick 2010), whereas the other study used "soft diet" as their definition (equivocal to a GOOSS score of 2) as the point of establishment of oral intake (Fiori 2013). Of the other primary outcome measure, one study reported on in-hospital mortality and cumulative survival (Mehta 2006). The other two studies reported median or mean survival (Fiori 2013; Jeurnick 2010).

Of the secondary outcome measures, all three studies reported on length of hospital stay and adverse events occurring as a result of the intervention. The timeframe for complications and which events were acknowledged as complications differed among the studies. Two studies reported on the recurrence of obstructive symptoms as a separate event, as well as the need for further intervention (Fiori 2013; Jeurnick 2010).

All studies assessed quality of life but used different scoring systems and selected different time points. The earliest study used the standardised 36-item Short Form (SF-36) questionnaire at the time of randomisation and at one month (Mehta 2006). They also used a visual analogue pain score before the intervention and on the first day postintervention. One study used the visual analogue scale and the EuroQol-5D (EQ-5D) standardised questionnaires at 14 days, one month and then every month thereafter (Jeurnick 2010). Participants completed a self-developed questionnaire on the burden of intervention, personal preference, pain and nausea. One study used their own scoring system to determine personal satisfaction assessed as good, fair or poor (Fiori 2013). Follow-up clinical examination was every three months and we, therefore, assumed that this assessment was undertaken at these time points.

The primary site of malignancy affects survival. One study focused only on GOO as a result of antropyloric malignancy (Fiori 2013). The remaining two studies included all malignant causes and in both of these studies pancreatic malignancy was responsible for the majority of cases (Jeurnick 2010; 74\%; Mehta 2006: 56\%).

The three trials randomised 84 participants. In the Jeurnick 2010 study, a high number of eligible patients declined to enter the trial due to a perceived perception that the non-surgical intervention was preferable. It was unclear if this was encountered in the other trials. About $55 \%$ of participants were men and $45 \%$ were women. One study had a marked gender differentiation with 13 men and five women (Fiori 2013). The mean age for all participants from the three studies was 68 years. Overall, 41 participants underwent surgical gastrojejunostomy, 25 participants had an open procedure and 16 participants had a laparoscopic procedure. Forty-three participants underwent duodenal stenting.

\section{Excluded studies}

Of the 43 full-text studies, we excluded 37. Twenty-five studies were retrospective studies (Abdellah-Fernandez 2015; Alonso-Larraga 2012; Arigami 2016; Chandrasegaram 2012; Del Piano 2005; ElShabrawi 2013; Jang 2017; Jeurnick 2007a; Keranen 2013; Khashab 2013; Kimura 2013; Kubota 2007; Maetani 2004; Maetani 2005; Mejia 2006; Mittal 2004; No 2013; Park 2015; Rudolph 2011; Tsauo 2016; Uemura 2018; Wong 2002; Yim 2001; Yoshida 2017; Yukimoto 2018). Eight studies were non-RCTs (Espinel 2006; Fiori 2016; Johnsson 2004; Schmidt 2009; Shimazaki 2013; Taniguchi 2014; Tsuchida 2013; Van Hooft 2009). Three studies (from four references) used different treatment options (Bukhari 2016; Kumagai 2016; PerezMiranda 2016).

\section{Studies awaiting classification}

We found no studies awaiting classification.

\section{Ongoing studies}

We found no ongoing studies.

\section{Risk of bias in included studies}

Overall, the studies were at low risk of bias as shown in Figure 2 and Figure 3, although performance bias was at high risk. 
Figure 2. Risk of bias graph: review authors' judgements about each risk of bias item presented as percentages across all included studies.

Random sequence generation (selection bias)

Allocation concealment (selection bias)

Blinding of participants and personnel (performance bias)

Blinding of outcome assessment (detection bias)

Incomplete outcome data (attrition bias)

Selective reporting (reporting bias)

Other bias
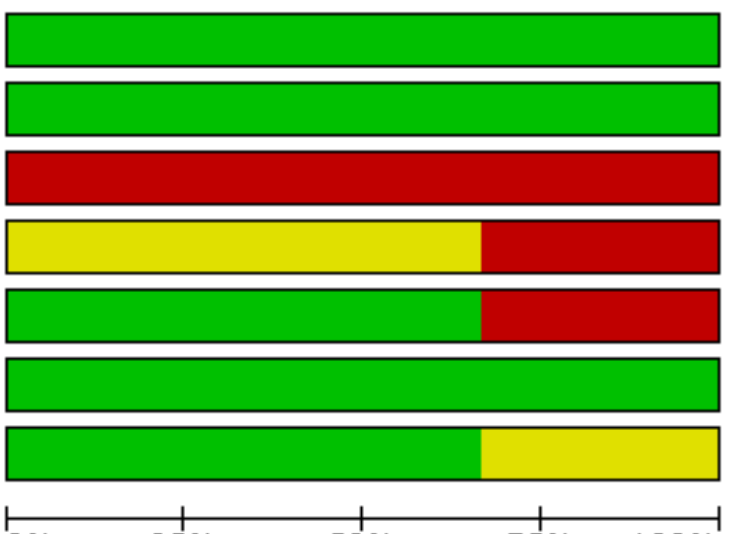

$0 \%$

$50 \%$

$75 \% \quad 100 \%$

Low risk of bias

Unclear risk of bias

High risk of bias 
Figure 3. Risk of bias summary: review authors' judgements about each risk of bias item for each included study.

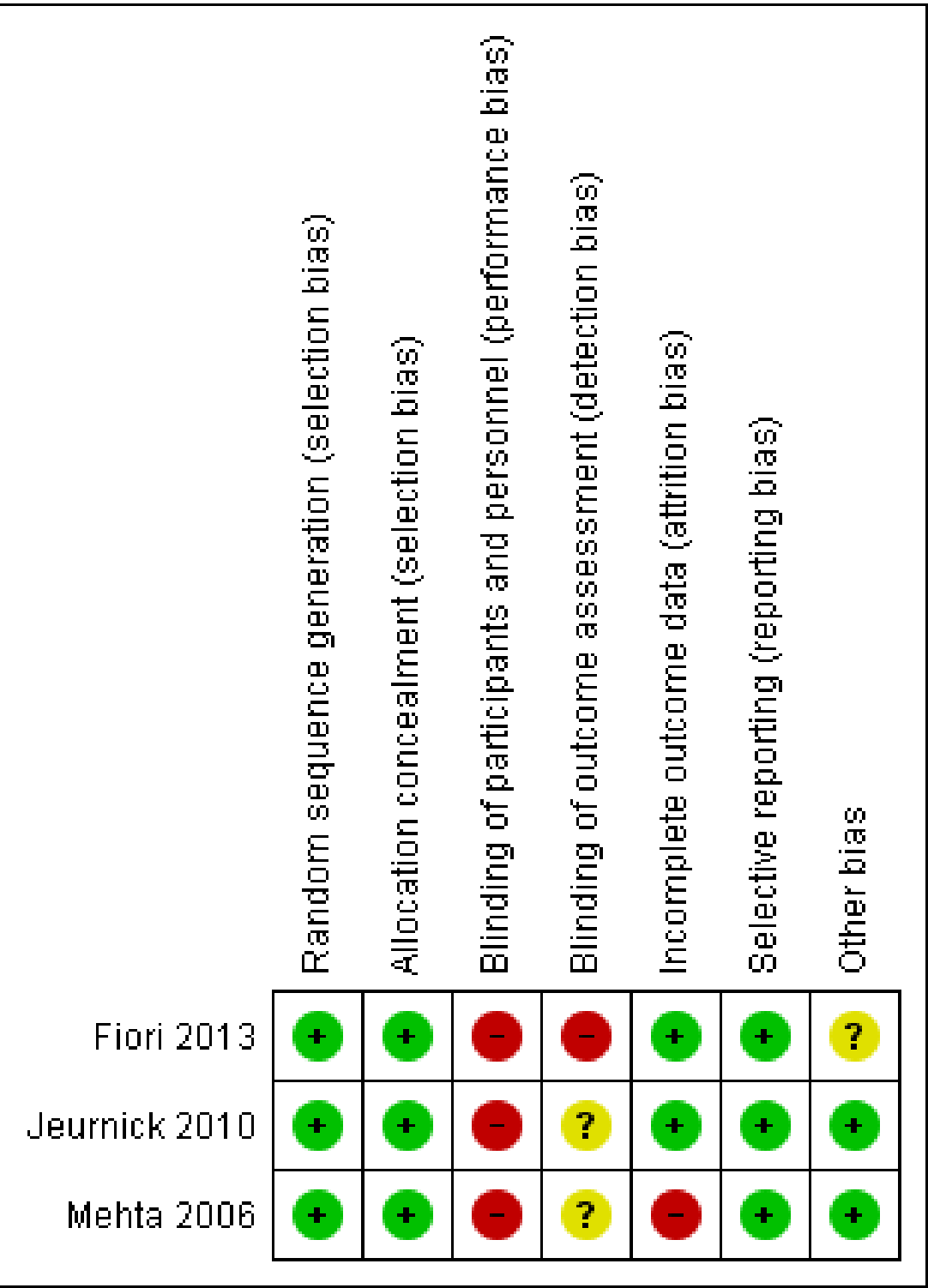

\section{Allocation}

Two studies used computer-generated lists for randomisation (Jeurnick 2010; Mehta 2006). The third study used tables of random numbers (Fiori 2013). The randomisation was either performed centrally (Jeurnick 2010) or was concealed from investigators at the time of randomisation (Fiori 2013; Mehta 2006). Therefore, all three studies were at low risk of selection bias

\section{Blinding}

All studies were at high risk of performance bias as participants were not and could not be blinded to the intervention they received. One study had a high risk of detection bias as the outcome assessment was performed by the surgeons who performed the procedure (Fiori 2013). It was unclear in the other two studies if the outcome assessors were blinded to the intervention that the person received and, hence, the risk of detection bias was unclear (Jeurnick 2010; Mehta 2006).

\section{Incomplete outcome data}

Two studies had complete data analysis and were at low risk of attrition bias (Fiori 2013; Jeurnick 2010). In the remaining study, it appeared that seven participants failed to complete the followup questionnaire at one month, although the exact number lost to follow-up and reasons were not documented, placing this study at potential high risk of attrition bias (Mehta 2006).

\section{Selective reporting}

All studies were at low risk of reporting bias as they documented all outcome measures.

\section{Other potential sources of bias}

One study included participants who had duodenal stenting via a percutaneous tract that may have an effect on a person's quality of life and complications (Mehta 2006). Two studies were well matched for age and sex and were at low risk of other bias (Jeurnick 2010; Mehta 2006). One study had a higher proportion of men, 
although the proportion of men and women in each arm of the trial were similar and was at unclear risk of other bias (Fiori 2013). There were no other sources of bias.

\section{Effects of interventions}

See: Summary of findings for the main comparison Duodenal stenting compared with surgical palliation for malignant gastric outlet obstruction

See Summary of findings for the main comparison for the main comparison.

\section{Primary outcomes}

\section{Measures of the resolution of symptoms}

Re-establishment of oral intake (technical success of the intervention)

Based on the difficulties and inaccuracies of analysing the time to re-establishment of oral intake, we recorded the technical success of the intervention. If technically successful, it was assumed that oral intake had resumed. All studies reported this outcome. Overall, duodenal stenting may have been less successful when compared to surgical palliation (RR $0.98,95 \% \mathrm{Cl} 0.88$ to $1.09 ; 3$ studies; 82 participants; $\mathrm{P}=0.70$; Analysis 1.1; low-quality evidence). At least one study had a low experience of duodenal stent placement prior to the study which may have impacted the results (Mehta 2006).

\section{Time to re-establishment of oral intake}

Two studies reported time to re-establishment of oral intake (Analysis 1.2) (Fiori 2013; Jeurnick 2010). Neither study reported the standard deviation, which was instead calculated from the P value. The Jeurnick 2010 study reported median time, which we assumed to be the same as the mean when calculating the standard deviation. This study reported that three participants had delayed gastric emptying and, thus, this may have affected the results. The assumption of normality for this outcome is, however, unlikely to be true so the results should be interpreted with caution.

Based on the difficulties and inaccuracies of analysing the time to re-establishment of oral intake, the technical success of the intervention was used as a proxy measure. If technically successful, it is assumed that oral intake had resumed. All three studies reported this outcome. Duodenal stenting was equally likely to be successful when compared to surgical palliation (RR 0.95, $95 \% \mathrm{Cl} 0.88$ to $1.09 ; \mathrm{P}=0.45$ ). As well as small numbers of participants, at least one study reported a low experience of duodenal stent placement prior to the study and two participants, early in the study, could not be stented and required conversion to a gastrojejunostomy (Mehta 2006).

\section{All-cause mortality}

Short-term mortality (in-hospital mortality, or mortality within three months)

No studies reported short-term mortality (i.e. mortality within three months following intervention). One study reported in-hospital mortality (Mehta 2006). We were uncertain of any difference between the two groups (RR $0.72,95 \% \mathrm{Cl} 0.14$ to $3.64 ; 27$ participants; $\mathrm{P}=0.69$; Analysis 1.3 ; very low-quality evidence). The study included only 27 participants, so we downgraded the quality of the evidence of this study to very low given the small sample size.
The remaining two studies reported mean survival following the intervention. One study reported median survival ( 56 days in the stent group and 78 days in the gastrojejunostomy group), from which we estimated the mean and standard deviation (Jeurnick 2010). We were uncertain of any differences in mean survival between interventions (MD -22.00 days, $95 \% \mathrm{Cl}-53.45$ to $9.45 ; 39$ participants; $\mathrm{P}=0.17$; Analysis 1.4 ). This evidence was of extremely low-quality because it was from a single study with an estimated standard deviation. The other study reported mean survival (258 days in the stent group and 283 days in the gastrojejunostomy group) and range of survival only and as a result, we could not calculate the standard deviation (Fiori 2013). This study reported a non-significant difference between the two groups.

\section{Secondary outcomes}

\section{Time to recurrence of obstructive symptoms}

Two studies reported the recurrence of obstructive symptoms (Fiori 2013; Jeurnick 2010). Recurrence was more likely following duodenal stent (RR 5.08, 95\% Cl 0.96 to 26.74; P 0.06; Analysis 1.5; moderate-quality evidence) (i.e. 13/43 participants needed a further procedure following duodenal stenting). The studies also reported the timeframe, although not for all cases and, thus, further analysis could not be completed. In the Jeurnick 2010 study, further endoscopy following duodenal stent placement occurred at 28 , $58,73,133$ and 148 days. A repeat endoscopy occurred following gastrojejunostomy although there was no abnormality identified and the time at which this occurred was not specified. In the Fiori 2013 study, the time of repeat endoscopy following duodenal stent was 31 and 110 days. Based on the small number of participants and range of time points recorded, it was impossible to ascertain an accurate mean time to recurrence of symptoms. This study stated a mean of 70 days to complications with a mean survival of 258 days. However, this mean is based on only nine participants and required extreme caution in its interpretation.

\section{Adverse events}

\section{Serious adverse events}

All three studies reported adverse events as well as the need for reintervention (Fiori 2013; Jeurnick 2010; Mehta 2006). We defined serious adverse events according to the Clavien-Dindo Classification as grade III and above (Clavien 2009; Dindo 2004), and according to the International Conference on Harmonisation (ICH-GCP 2015), as any untoward medical occurrence that resulted in death, was life-threatening or prolonged the existing inpatient hospitalisation. It was unclear whether many of the adverse events reported prolonged hospitalisation, thus we used the Clavien-Dindo classification only for adverse events. We selected the timeframe of three months, but aside from immediate postprocedure complications, the timeframe was not always apparent and it was assumed to be within three months.

We were uncertain whether there was a difference between the occurrence of serious adverse events (RR $1.15,95 \% \mathrm{Cl} 0.33$ to 3.98; 3 studies; 84 participants; Analysis 1.6; very low-quality evidence). It must be emphasised that the total number of events and participants was extremely low. The only reported major complication following surgical palliation was a second laparotomy for postoperative bleeding. The other serious adverse events in this group were from the Mehta 2006 study and were postoperative deaths. There were three deaths in the surgical group (secondary 
to pneumonia, sepsis and carcinomatosis). Although one death occurred prior to the intervention, we included it in this group based on an intention to treat analysis. Serious adverse events in the duodenal stent group consisted of a second endoscopy for stent migration or blockage (or both), which were relieved by another stent. Two participants from the Mehta 2006 study died in the postoperative procedure secondary due to carcinomatosis. There were no in-hospital postintervention deaths in two studies (Fiori 2013; Jeurnick 2010).

As the most common serious adverse event was the need for reintervention and the timeframe for this was unclear, we analysed the need for reintervention at any time point separately. All included studies reported the need for further interventions in the follow-up period. Further intervention in the form of a repeat endoscopy may have been less common following surgical palliation (RR 4.71, Cl 1.36 to 16.30; 3 studies; 84 participants; very low-quality evidence). When required, repeat endoscopy following duodenal stenting found an obstructing food bolus or overgrowth of tumour into the stent, which was treated with removal of the obstructing food bolus and placement of a second stent. Two participants in the Jeurnick 2010 study required surgical palliation following an initial duodenal stent, although it was unclear why this was necessary from the reported information. It is imperative to remember that the number of participants in this analysis were small, so the findings need to be interpreted with caution.

\section{Minor adverse events}

All three studies reported minor complications (Fiori 2013; Jeurnick 2010; Mehta 2006). We used the Clavien-Dindo classification of grade I and II complications (Clavien 2009; Dindo 2004). It was unclear if all studies included prolonged resumption of oral intake or ileus (or both) as a complication, so we excluded this as a complication. We were uncertain whether minor adverse complications were more common following surgical palliation than following duodenal stenting (RR $0.35,95 \% \mathrm{Cl} 0.07$ to 1.61 ; 3 studies; 84 participants; Analysis 1.8; $\mathrm{P}=0.18$; very lowquality evidence). Minor adverse events included haematemesis, wound infection, urinary tract infection, deep vein thrombosis and pneumonia. As with serious adverse events, the number of participants was extremely low resulting in a very low confidence for this assumption.

\section{Length of hospital stay}

All three studies reported the length of hospital stay (Fiori 2013; Jeurnick 2010; Mehta 2006). The length of hospital stay may have been shorter for people in the duodenal stenting group compared to the surgical palliation group (MD -6.70 days, $95 \% \mathrm{Cl}-9.41$ to -3.98; 3 studies; 84 participants; Analysis 1.9; $P<0.00001$; moderatequality evidence). In Jeurnick 2010, we calculated the standard deviation from the P value and in Mehta 2006, we calculated the standard deviation from the standard error. When these studies were excluded, the remaining study also found a shorter stay for people in the duodenal stent group, although the numbers in this study were extremely low (Mehta 2006).

\section{Health-related quality of life}

Although all three studies assessed quality of life, they used different methods and, hence, no analysis was possible. Fiori 2013 rated participant satisfaction as fair or good, although it did not clarify how they made this rating or what a 'fair' and 'good' rating meant. The timing of this rating following intervention was not clear; however, it did state that there was no difference between the two interventions. Mehta 2006 completed the SF-36 questionnaire at one month. This found a higher mean physical health score in the duodenal stent group, but there was no difference in the mental health score. The Jeurnick 2010 study had the most comprehensive quality of life assessment with a health-related quality of life score taken every 30 days up to 150 days. Up to this point, there was no difference recorded in participant satisfaction, participant preferences and burden of treatment. However, no conclusions could be made based on the small numbers in each study.

\section{DISCUSSION}

In this review, we compared duodenal stent placement with surgical palliation in the form of a gastrojejunostomy for people with GOO secondary to an unresectable malignant process. People presenting with GOO have a limited life expectancy and, thus, the resolution of symptoms with minimal hospital stay and complications is a priority.

\section{Summary of main results}

There may be have been little to no difference between duodenal stenting and surgical palliation in the technical success of the procedure. The time to resumption of oral intake may have been shorter with an MD of approximately three days for people who had undergone duodenal stent placement. This was based on lowquality evidence as the number of participants with this outcome recorded was small with only 57 participants from two RCTs included (Fiori 2013; Jeurnick 2010). Gastrojejunostomy resulted in a new anatomical configuration, which alongside effects from fluid shifts that were a result of the operation itself, was likely to result in delayed gastric emptying and, hence, a longer time until resumption of oral intake.

The surgical arms in these studies comprised of mixed laparoscopic (two cases) and open procedures (16 cases) (Jeurnick 2010), and only open procedures (nine cases) (Fiori 2013). Previous studies have found laparoscopic gastrojejunostomy to be more favourable in terms of an early tolerance to oral intake (Navarra 2006), although the numbers were also small. In this meta-analysis, there were insufficient numbers to perform subgroup analyses between open and laparoscopic gastrojejunostomy. Therefore, the predominance of open surgical palliation may have skewed the results further in favour of duodenal stenting.

People presenting with malignant $\mathrm{GOO}$ are generally frail with poor nutritional and physiological reserve. We are uncertain if there was a difference in all-cause mortality between the two interventions, although the number of events was very low.

Two studies reported on median survival (Fiori 2013; Jeurnick 2010), although only one study provided sufficient information to be included (Jeurnick 2010). This study found a non-significant longer survival following duodenal stenting. This result must be interpreted with extreme caution as the results were from a single, RCT with a low number of participants. This study included people who had $\mathrm{GOO}$ as a result of any underlying primary malignancy. The median survival varies for different malignancies and it is, thus, more likely that survival is a reflection of the underlying disease process as opposed to the intervention. 
An important consideration in the assessment of which intervention is preferable is the recurrence of symptoms and, hence, the need for further intervention. Time to recurrence of the symptoms of GOO may have been more likely in people who had a duodenal stent with an RR of $5.08(P=0.06)$. Given the small number of included studies and small number of events, this was not surprising.

Adverse events occurring as a result of the intervention will likely have a significant impact on the person's recovery, length of hospital stay and subsequent quality of life. We were uncertain if there were differences in the occurrence of serious adverse events. The need for further intervention was more likely in people who had a duodenal stent. Stent blockages due to tumour overgrowth have been found to be reasonably common in other reviews and reported to occur in $15 \%$ to $20 \%$ of people (Dormann 2004). We were also uncertain about the difference in the occurrence of minor adverse events. Although not specifically indicated, an increase in the occurrence of minor adverse events is likely to have lengthened the hospital stay.

The studies included in this review used either covered (Fiori 2013) or uncovered duodenal stents (Jeurnick 2010; Mehta 2006). Previous work has shown differing rates of stent blockage and migration for covered and uncovered stents. There were not enough participants in the included studies to compare the two stent types and this may have impacted on the large Cls seen for this outcome.

Length of hospital stay is an important factor when considering the impact of an intervention on quality of life. A longer hospital stay may also increase the frailty of the person due to loss of muscle mass and strength as a result of reduced mobility. It is unknown whether this impacts long-term survival.

The timeframe of stent problems, when reported, was broad, likely reflecting both the small number of participants and underlying malignancy processes. Different primary malignancies may be more likely to result in tumour overgrowth and have a higher risk of stent blockage. In addition, people with a longer expected survival have a greater timeframe in which tumour overgrowth can occur. Subgroup analysis, if numbers had allowed, may have helped to ascertain if the same treatment approach was suitable for the different primary malignancies.

It was not possible to analyse the impact on quality of life each intervention had for these participants.

\section{Overall completeness and applicability of evidence}

Considering the small number of studies included, alongside the small sample sizes and variable study design, the confidence in the outcomes and the overall applicability of this meta-analysis has significant limitations.

Two of the RCTs included GOO as a result of any primary malignancy (Jeurnick 2010; Mehta 2006), whereas the third study included antropyloric malignancies only (Fiori 2013). The anticipated survival of people with $\mathrm{GOO}$ is dependent on the underlying cancer, with pancreatic cancer having a shorter mean survival than gastric or duodenal cancer. In addition, there were no reports on whether the likelihood of stent blockage or migration varied according to the underlying malignancy. Therefore, it may be that the outcomes between duodenal stenting and surgical palliation differ depending on the underlying primary malignancy and anticipated survival. Previous studies have suggested that where survival is anticipated to be longer, surgical palliation is the preferred treatment option due to the lower recurrence risk (Jeurnick 2011).

The site of the primary malignancy also has an impact on the likelihood of biliary obstruction. Placement of a stent at the ampulla of Vater may impede access to the common bile duct via an endoscopic retrograde cholangiopancreatogram. People who later develop biliary obstruction may then require percutaneous transhepatic drainage with a potential greater impact on their quality of life. No studies comprehensively reported on the presence of biliary obstruction, at pre-, peri- or postprocedure, as well as the interventions required and any impact on outcomes, including quality of life. The presence or high likelihood of biliary obstruction may have an impact on decision-making in deciding on the best intervention for the person.

Several duodenal stents are available, primarily consisting of covered and non-covered SEMS. The three RCTs used different stents and, it was impossible to ascertain how this impacted the outcomes. Other studies suggested that stent migration is more frequent with a covered stent (Pan 2014); however, stent obstruction is lower with this type of stent (Pan 2014). Newer covered stents with an antimigration design have shown comparable migration rates and increased patency rates when compared to uncovered stents (Lee 2015).

As people in this review were undergoing palliative procedures, quality of life is of paramount importance. Although all the studies reported on quality of life, there was substantial heterogeneity in the method and timeframe used and, thus, a meta-analysis could not be performed. One study reported that $50 \%$ of eligible people refused to enter the RCT as they wanted to have a duodenal stent as opposed to an operation (Jeurnick 2010). This may reflect the underlying factors that people find important in terms of avoidance of an anaesthetic and shorter hospital stay; however, it is unclear whether these factors affect quality of life. This underlying bias may have impacted the results of non-randomised trials that are present in the literature.

Recurrence and the need for a repeat endoscopic intervention is a major complication of duodenal stenting. It is unclear how significant this is on quality of life for the person and the likelihood of complications following a second endoscopy. For some people, this may have less of an impact than, for example, a slightly longer time to begin an oral diet and a longer hospital stay after the first intervention. Studies that measure quality of life at regular intervals are required to ascertain the impact of any recurrence and need for repeat intervention on these people.

\section{Quality of the evidence}

In regards to the quality of the evidence, all studies were at an overall low risk of bias. All studies were at low risk of selection bias and reporting bias. The over-riding difficulty was the high risk of performance bias. It is impossible to blind the participants to the intervention they received. However, in some studies, the outcome assessor was not blinded to the intervention or it was unclear whether they were blinded or not.

Heterogeneity was variable for the outcomes measured and, due to the small number of studies included, it must be interpreted 
with caution. Dichotomous outcomes such as recurrence and reintervention rates had a low level of heterogeneity (recurrence: $\mathrm{Chi}^{2}=0.08$; reintervention rates: 0.09). However, adverse event outcomes showed a higher heterogeneity for minor $\left(\mathrm{Chi}^{2}=3.08\right)$ and serious adverse events $\left(\mathrm{Chi}^{2}=1.71\right)$. This heterogeneity is likely due to variable definitions used in the different studies.

Two studies included people with malignant GOO that was the result of any underlying malignancy with the majority of people in these studies having a pancreatic carcinoma (Jeurnick 2010; Mehta 2006). The other study included only people with gastric adenocarcinoma, resulting in an inconsistency between study participants (Fiori 2013). However, the participants in the studies were consistent with the population in question in this review.

Overall, the number of participants in this systematic review was low, which will affect the precision of the findings. The Cls for some of the outcomes were sizeable, for example, ranging from -9.45 to -53.45 days for the outcome of median survival, which can be explained by the low number of participants with this outcome recorded (39). The outcome for re-establishment of oral intake had smaller Cls; however, this spanned the line of no effect. It was impossible to determine if this was due to there being no difference or due to imprecision in the data.

Overall, there were serious shortcomings in the quality of evidence, primarily due to inconsistent reporting of outcomes between studies, the risk of performance bias and the low numbers of participants. However, these studies do constitute the best level of evidence that is currently available to address the question of this review.

\section{Potential biases in the review process}

We followed the Cochrane Handbook for Systematic Reviews of Interventions for this review (Higgins 2011). There were no language, publication status or sample size restrictions.

\section{Agreements and disagreements with other studies or reviews}

This is the first Cochrane Review to compare stent placement versus surgical palliation for the management of malignant GOO.

The search identified eight previous systematic reviews and meta-analyses that all included a selection of randomised, nonrandomised or retrospective trials (Bian 2016; Hosono 2007; Jeurnick 2007b; Ly 2010; Minata 2016; Nagaraja 2014; Siddiqui 2007; Zheng 2012). All, except one (Bian 2016), included people with malignant $\mathrm{GOO}$ secondary to any primary malignancy.

All reviews that reported on the time to resumption of oral intake showed a shorter timeframe with duodenal stenting that is in agreement with our meta-analysis (Bian 2016; Hosono 2007; Jeurnick 2007b; Ly 2010; Zheng 2012). Five reviews that reported hospital stay found a shorter stay following duodenal stent (Bian 2016; Hosono 2007; Jeurnick 2007b; Ly 2010; Nagaraja 2014) which is in accordance with our data, although we were uncertain of this finding. In three reviews, recurrence or reintervention was higher in the duodenal stenting group (Bian 2016; Jeurnick 2007b; Minata 2016). Of interest, the review that focused solely on gastric carcinoma found a longer patency with gastrojejunostomy, indicating that longer survival corresponded to a higher risk of recurrence in people treated with a duodenal stent (Bian 2016).

This meta-analysis found no significant difference in the rate of serious adverse events, although we were uncertain of this finding. In addition, this meta-analysis found a significant difference in minor adverse events with an RR of 0.35 in favour of reduced events in people who had undergone duodenal stenting, although we were uncertain of this finding. Previous reviews found conflicting results with the majority showing equivocal complication rates between the two interventions (Jeurnick 2007b; Ly 2010; Minata 2016; Nagaraja 2014; Zheng 2012). These conflicting results were likely due, in part, to the different definitions used and the variable inclusion and grading of recurrence as an adverse event.

Although our results were generally in line with other published systematic reviews and meta-analyses, the majority of studies used in these reviews were the same, with the majority of participants being from retrospective studies. Therefore, caution must be used when interpreting the results.

\section{AUTHORS' CONCLUSIONS}

\section{Implications for practice}

Endoscopic duodenal stenting has the potential advantage of a quicker resumption of oral intake and a decreased length of hospital stay. However, the reintervention rate is higher due to recurrence of symptoms secondary to stent blockage or migration. Given this, where survival is anticipated to be longer (i.e. for certain malignancies), gastrojejunostomy may be the preferred intervention.

Further randomised controlled trials that compare endoscopic stenting to open and laparoscopic surgery with subgroup analysis based on the underlying primary malignancy are required to fully establish the role of these interventions.

\section{Implications for research}

Further randomised trials are required to ascertain:

- whether open or laparoscopic gastrojejunostomy affects the outcomes;

- whether the type of duodenal stent affects the outcomes;

- whether the primary underlying malignancy and the likely survival affects the outcomes.

\section{ACKN OWLEDGEMEN TS}

We would like to thank Karin Dearness, Managing Editor, Cochrane Upper Gastrointestinal and Pancreatic Diseases Group (UGPD) for providing administrative and logistical support for the conduct of the current review, and Yuhong Yuan, Trials Search Co-ordinator, Cochrane UGPD Group for developing and executing the search strategies.

We would also like to thank the peer reviewers, copy editors and Cochrane Editorial Unit for their comments. 


\section{RE F E R E N C E S}

\section{References to studies included in this review}

Fiori 2013 \{published data only\}

* Fiori E, Lamazza A, DeMasi E, DeCesare A, Schillaci A, Sterpetti A. Endoscopic stenting for gastric outlet obstruction in patients with unresectable antro pyloric cancer. Systematic review of the literature and final results of a prospective study. The point of view of a surgical group. American Journal of Surgery 2013;206:210-7.

Fiori E, Lamazza A, Volpino P, Burza A, Paparelli C, Cavallaro G, et al. Palliative management of malignant antro-pyloric strictures. Gastroenterostomy vs. endoscopic stenting. A randomised prospective trial. Anticancer Research 2004;24:269-72.

\section{Jeurnick 2010 \{published data only\}}

* Jeurnick SM, Steyerberg EW, van Hooft JE, van Eijck CHJ, Schwartz MP, Vleggaar FP, et al. Surgical gastrojejunostomy or endoscopic stent placement for the palliation of malignant gastric outlet obstruction (SUSTENT study): a multicentre randomized trial. Gastrointestinal Endoscopy 2010;71(3):490-9.

Jeurnink SM, Polinder S, Steyerberg EW, Kuipers EJ, Siersema PD. Cost comparison of gastrojejunostomy versus duodenal stent placement for malignant gastric outlet obstruction. Journal of Gastroenterology 2010;45:537-43.

Jeurnink SM, Steyerberg EW, Vleggaare FP, van Eijck CHJ, van Hooft JE, Schwartz MP, et al. Predictors of survival in patients with malignant gastric outlet obstruction: a patientoriented decision approach for palliative treatment. Digestive and Liver Disease 2011;43:548-52.

\section{Mehta 2006 \{published data only\}}

Mehta S, Hindmarsh A, Cheong E, Cockburn J, Saada J, Tighe R, et al. Prospective randomised trial of laparoscopic gastrojejunostomy versus duodenal stenting for malignant gastric outflow obstruction. Surgical Endoscopy 2006;20:239-42.

\section{References to studies excluded from this review}

\section{Abdellah-Fernandez 2015 \{published data only\}}

Abdellah-Fernandez O, Parreno-Manchado FC, GarciaPlaza A, Alvarez-Delgado A. Partial stomach partitioning gastrojejunostomy in the treatment of the malignant gastric outlet obstruction. Cirugia y Cirujanos 2015;83(5):386-92.

\section{Alonso-Larraga 2012 \{published data only\}}

Alonso-Larraga JO, Alvaro J, Sobrino-Cossio S, HernándezGuerrero A, de la Mora-Levy G, Figueroa-Barojas P. Selfexpanding metal stents versus antrectomy for the palliative treatment of obstructive adenocarcinoma of the gastric antrum. Revista Espanola de Enfermedades Digestivas 2012;104(4):185-9.

\section{Arigami 2016 \{published data only\}}

Arigami T, Uenosono Y, Ishigami S, Yanagita S, Okubo K, Uchikado Y, et al. C Clinical impact of stomach-partitioning gastrojejunostomy with braun enteroenterostomy for patients with gastric outlet obstruction caused by unresectable gastric cancer. Anticancer Research 2016;36(10):5431-6.

\section{Bukhari 2016 \{published data only\}}

Bukhari M, Itoi T, Elzein M, Baron TH, Nieto J, Chen Y, et al. International multicenter comparative trial of endoscopic ultrasonography guided gastroenterostomy versus surgical gastrojejunostomy for the treatment of malignant gastric outlet obstruction. Gut 2016;4(5 Suppl 1):A408-9.

\section{Chandrasegaram 2012 \{published data only\}}

Chandrasegaram MD, Eslick GD, Mansfield CO, Liem H, Richardson M, Ahmed S, et al. Endoscopic stenting versus operative gastrojejunostomy for malignant gastric outlet obstruction. Surgical Endoscopy 2012;26:323-9.

Del Piano 2005 \{published data only\}

Del Piano M, Ballare M, Montino F, Todesco A, Orsello M, Magnani $C$, et al. Endoscopy or surgery for malignant $\mathrm{Gl}$ outlet obstruction?. Gastrointestinal Endoscopy 2005;61:421-6.

\section{El-Shabrawi 2013 \{published data only\}}

El-Shabrawi A, Cerwenka H, Bacher H, Kornprat P, Schweiger J, Mischinger $\mathrm{HJ}$. Treatment of malignant gastric outlet obstruction: endoscopic implantation of self-expanding metal stents versus gastric bypass surgery. European Surgical Research 2013;38(6):451-5.

\section{Espinel 2006 \{published data only\}}

Espinel J, Sanz O, Vivas S, Jorquera F, Munoz F, Olcoz JL, et al. Malignant gastrointestinal obstruction: endoscopic stenting versus surgical palliation. Surgical Endoscopy 2006;20:1083-7.

\section{Fiori 2016 \{published data only\}}

Fiori E, Sterpetti AV, De Cesare A, Lamazza A. Factors leading to improved results for endoscopic stenting for metastatic antropyloric adenocarcinoma. A comparison with gastrojejunostomy. Journal of Gastrointestinal Surgery 2016;20:1802-6.

\section{Jang 2017 \{published data only\}}

Jang SH, Lee H, Min BH, Kim SM, Kim HS, Carriere KC, et al. Palliative gastrojejunostomy versus endoscopic stent placement for gastric outlet obstruction in patients with unresectable gastric cancer: a propensity score-matched analysis. Surgical Endoscopy 2017;31(10):4217-23.

\section{Jeurnick 2007a \{published data only\}}

Jeurnick SM, Steyerberg EW, Hof G, Van Eijck CHJ, Kuipers EJ, Siersema PD. Gastrojejunostomy versus stent placement in patients with malignant gastric outlet obstruction: a comparison in 95 patients. Journal of Surgical Oncology 2007;96(5):389-96.

\section{Johnsson 2004 \{published data only\}}

Johnsson E, Thune A, Liedman B. Palliation of malignant gastroduodenal obstruction with open surgical bypass or endoscopic stenting: clinical outcome and health economic evaluation. World Journal of Surgery 2004;28:812-7. 


\section{Keranen 2013 \{published data only\}}

Keranen I, Kylanpa A, Udd M, Louhimo J, Lepisto A, Halttunen J, et al. Gastric outlet obstruction in gastric cancer: a comparison of three palliative methods. Journal of Surgical Oncology 2013;108:537-41.

\section{Khashab 2013 \{published data only\}}

Khashab M, Ahmad S, Alawad AS, Shin EJ, Kim K. Enteral stenting versus gastrojejunostomy for palliation of malignant gastric outlet obstruction. Surgical Endoscopy 2013;27:2068-75.

\section{Kimura 2013 \{published data only\}}

Kimura Y, Taniguchi H, Yamamoto M, Fujita J, Fujita S, Kishibuchi M, et al. Efficacy of endoscopic gastroduodenal stenting for gastric outlet obstruction caused by unresectable gastric cancer. Gan to Kagaku Ryoho. Cancer \& Chemotherapy 2013;40(12):1687-9.

\section{Kubota 2007 \{published data only\}}

Kubota K, Kuroda J, Origuchi N, Kaminishi M, Isayama I, Kawabe T, et al. Stomach-partitioning gastrojejunostomy for gastroduodenal outlet obstruction. Archives of Surgery 2007;142(7):607-11.

\section{Kumagai 2016 \{published data only\}}

Kumagai K, Rouvelas I, Ernberg A, Persson S, Analatos A, Mariosa $D$, et al. A systematic review and meta-analysis comparing partial stomach partitioning gastrojejunostomy versus conventional gastrojejunostomy for malignant gastroduodenal obstruction. Langenbecks Archives of Surgery 2016;401(6):777-85.

\section{Maetani 2004 \{published data only\}}

Maetani I, Tada T, Ukita T, Inoue H, Sakai Y, Nagao J. Comparison of duodenal stent placement with surgical gastrojejunostomy for palliation in patients with duodenal obstructions caused by pancreaticobiliary malignancies. Endoscopy 2004;36(1):73-8.

\section{Maetani 2005 \{published data only\}}

Maetani I, Akatsuka S, Ikeda M, Tada T, Ukita T, Nakamura Y, et al. Self-expandable metallic stent placement for palliation in gastric outlet obstructions caused by gastric cancer: a comparison with surgical gastrojejunostomy. Journal of Gastroenterology 2005;40:932-7.

\section{Mejia 2006 \{published data only\}}

Mejía A, Ospina J, Muñoz A, Albis R, Oliveros R. Palliation of a malignant gastroduodenal obstruction. Revista Colombiana de Gastroenterologia 2006;21(1):17-21.

\section{Mittal 2004 \{published data only\}}

Mittal A, Windsor J, Woodfield J, Casey P, Lane M. Matched study of three methods for palliation of malignant pyloroduodenal obstruction. British Journal of Surgery 2004;91:205-9.

\section{No 2013 \{published data only\}}

No JH, Kim SW, Lim CH, Kim JS, Cho YK, Park JM, et al. Longterm outcome of palliative therapy for gastric outlet obstruction caused by unresectable gastric cancer in patients with good performance status: endoscopic stenting versus surgery. Gastrointestinal Endoscopy 2013;78:55-62.

\section{Park 2015 \{published data only\}}

Park CH, Park JC, Kim EH, Chung H. Impact of carcinomatosis and ascites status on long-term outcomes of palliative treatment for patients with gastric outlet obstruction caused by unresectable gastric cancer: stent placement versus palliative gastrojejunostomy. Gastrointestinal Endoscopy 2015;81:321-32.

Perez-Miranda 2016 \{published data only\}

Perez-Miranda M, Tyberg A, Poletto D, Toscano E, Gaidhane M, Desai AP, et al. EUS guided gastrojejunostomy versus laparoscopic gastrojejunostomy: an international collaborative study. Journal of Clinical Gastroenterology 2017;51(10):896-99.

Perez-Miranda M, Tyberg A, Sharaiha RZ, Toscano E. EUS guided gastrojejunostomy versus laparoscopic gastrojejunostomy: an international collaborative study. Gastrointestinal Endoscopy 2016;83(55):175-6.

Rudolph 2011 \{published data only\}

Rudolph HU, Post S, Schlüter M, Seitz U, Soehendra N, Kähler G. Malignant gastroduodenal obstruction: retrospective comparison of endoscopic and surgical palliative therapy. Scandinavian Journal of Gastroenterology 2011;46:583-90.

\section{Schmidt 2009 \{published data only\}}

Schmidt C, Gerdes H, Hawkins W, Zucker E. A prospective observational study examining quality of life in patients with malignant gastric outlet obstruction. American Journal of Surgery 2009;198:92-9.

\section{Shimazaki 2013 \{published data only\}}

Shimazaki A, Katsube T, Usuda A, Miyaki A, Asaka S, Yamaguchi $\mathrm{K}$, et al. Examination of stent treatment and bypass surgery for unresectable advanced gastric cancer. Gan to Kagaku Ryoho. Cancer \& Chemotherapy 2013;40(12):1693-95.

\section{Taniguchi 2014 \{published data only\}}

Taniguchi H, Tamura S, Takeno A, Sato Y, Morimoto Y, Kusama H, et al. Efficacy of endoscopic gastroduodenal stenting for unresectable gastric cancer with gastric outlet obstruction. Gan to Kagaku Ryoho. Cancer \& Chemotherapy 2014;41(12):2334-6.

\section{Tsauo 2016 \{published data only\}}

Tsauo J, Yoo MW, Song HY, Hwang DW, Park JH, Ryu MH, et al. Partially-covered stent placement versus surgical gastrojejunostomy for the palliation of malignant gastroduodenal obstruction secondary to pancreatic cancer. Abdominal Radiology 2016;41:2233-40.

Tsuchida 2013 \{published data only\}

Tsuchida K, Kunisaki C, Shirai J, Watanabe T, Ono H, Oshima T, et al. The clinical outcomes of endoscopic stent placement for patients with malignant gastric outlet obstruction - a comparison with gastrojejunostomy. Gan to Kagaku Ryoho. Cancer \& Chemotherapy 2013;40(12):1690-2.

\section{Uemura 2018 \{published data only\}}

Uemura S, Iwashita T, Iwata K, Mukai T, Osada S, Sekino T, et al. Endoscopic duodenal stent versus surgical gastrojejunostomy for gastric outlet obstruction in patients with advanced 
pancreatic cancer. Pancreatology 2018 May 3 [Epub ahead of print]. [DOI: 10.1016/j.pan.2018.04.015]

\section{Van Hooft 2009 \{published data only\}}

Van Hooft JE, Uitdehaag MJ, Bruno MJ, Timmer R, Siersema PD, Dijkgraaf MGW, et al. Efficacy and safety of the new WallFlex enteral stent in palliative treatment of malignant gastric outlet obstruction (DUOFLEX study): a prospective multicenter study. Gastrointestinal Endoscopy 2009;69:1059-66.

Wong 2002 \{published data only\}

Wong YT, Brams DM, Munson L, Sanders L, Heiss F, Chase M, et al. Gastric outlet obstruction secondary to pancreatic cancer surgical vs endoscopic palliation. Surgical Endoscopy 2002;16:310-2

Yim 2001 \{published data only\}

Yim HB, Jacobson BC, Saltzman JR, Johannes RS, Bounds BC, Lee $\mathrm{JH}$, et al. Clinical outcome of the use of enteral stents for palliation of patients with malignant upper $\mathrm{Gl}$ obstruction. Gastrointestinal Endoscopy 2001;53:329-32.

\section{Yoshida 2017 \{published data only\}}

Yoshida Y, Fukutomi A, Tanaka M, Sugiura T, Kawata N, Kawai S, et al. Gastrojejunostomy versus duodenal stent placement for gastric outlet obstruction in patients with unresectable pancreatic cancer. Pancreatology 2017;17(6):983-9.

\section{Yukimoto 2018 \{published data only\}}

Yukimoto T, Morisaki T, Komukai S, Yoshida H, Yamaguchi D, Tsuruoka N, et al. The palliative effect of endoscopic uncovered self-expandable metallic stent placement versus gastrojejunostomy on malignant gastric outlet obstruction: a pilot study with a retrospective chart review in Saga, Japan. Internal Medicine 2018 Feb 9 [Epub ahead of print]. [DOI: 10.2169/internalmedicine.0171-17]

\section{Additional references}

\section{ASA 2014}

American Society of Anesthesiologists. ASA physical status classification system, 2014. www.asahq.org/resources/clinicalinformation/asa-physical-status-classification-system (accessed 8 December 2016)

\section{Bian 2016}

Bian SB, Shen WS, Xi HQ, Wei B, Chen L. Palliative therapy for gastric outlet obstruction caused by unresectable gastric cancer: a meta-analysis comparison of gastrojejunostomy with endoscopic stenting. Chinese Medical Journal 2016;129(9):1113-21.

\section{Bijen 2009}

Bijen CB, Vermeulen KM, Mourits MJ, de Bock GH. Costs and effects of abdominal versus laparoscopic hysterectomy: systemic review of controlled trials. PloS One 2009;4(10):e7340.

\section{Chowdhury 1996}

Chowdhury A, Dhali GK, Banerjee PK. Etiology of gastric outlet obstruction. American Journal of Gastroenterology 1996;91(8):1679.

\section{Clavien 2009}

Clavien PA, Barkun J, de Oliveira ML, Vauthey JN, Dindo D, Schulick RD, et al. The Clavien-Dindo classification of surgical complications: five year experience. Annals of Surgery 2009;250(2):187-96.

\section{Dindo 2004}

Dindo D, Demarties N, Clavien PA. Classification of surgical complications: a new proposal with evaluation in a cohort of 6336 patients and results of a survey. Annals of Surgery 2004;240(2):205-13.

\section{Doberneck 1987}

Doberneck RC, Berndt GA. Delayed gastric emptying after palliative gastrojejunostomy for carcinoma of the pancreas. Archives of Surgery 1987;122:827-9.

\section{Dormann 2004}

Dormann A, Meisner S, Verin N, Wenk LA. Self-expanding metal stents for gastroduodenal malignancies: systematic review of their clinical effectiveness. Endoscopy 2004;36:543-50.

\section{Espinel 2001}

Espinel J, Vivas S, Munoz F, Olcoz JL. Palliative treatment of malignant obstruction of gastric outlet using an endoscopically placed enteral Wallstent. Digestive Diseases and Sciences 2001;46:2322-4.

\section{GRADEpro GDT [Computer program]}

GRADE Working Group, McMaster University. GRADEpro GDT. Version (accessed 8 December 2016). Hamilton (ON): GRADE Working Group, McMaster University, 2015.

\section{Gurusamy 2013}

Gurusamy KS, Kumar S, Davidson B. Prophylactic gastrojejunostomy for unresectable periampullary carcinoma. Cochrane Database of Systematic Reviews 2013, Issue 2. [DOI: 10.1002/14651858.CD008533.pub3]

\section{Higgins 2011}

Higgins JP, Green S, editor(s). Cochrane Handbook for Systematic Reviews of Interventions Version 5.1.0 (updated March 2011). The Cochrane Collaboration, 2011. Available from handbook.cochrane.org.

\section{Hosono 2007}

Hosono S, Ohtani H, Arimoto Y, Kanamiya Y. Endoscopic stenting versus surgical gastroenterostomy for palliation of malignant gastroduodenal obstruction: a meta-analysis. Journal of Gastroenterology 2007;42:283-90.

\section{ICH-GCP 2015}

International Conference on Harmonisation of Technical Requirements for Registration of Pharmaceuticals for Human Use. Code of Federal Regulation and ICH Guidelines. Media (PA): Barnett, 2015.

\section{Isla 2000}

Isla AM, Worthington T, Kakkar AK, Williamson RC. A continuing role for surgical bypass in the palliative treatment of pancreatic carcinoma. Digestive Surgery 2000;17:143-6. 


\section{Jeurnick 2007b}

Jeurnink S, van Eijck C, Steyerberg E, Kuipers E. Stent versus gastrojejunostomy for the palliation of gastric outlet obstruction: a systematic review. BMC Gastroenterology 2007;7(18):1-10.

\section{Johnson 1990}

Johnson CD, Ellis H. Gastric outlet obstruction now predicts malignancy. British Journal of Surgery 1990;77(9):1023.

\section{Johnson 1995}

Johnson CD. Gastric outlet obstruction malignant until proved otherwise. American Journal of Gastroenterology 1995;90(10):1740.

\section{Keus 2006}

Keus F, De Jong JA, Gooszen HG, Van Laarhoven CJ. Laparoscopic versus open cholecystectomy for patients with symptomatic cholecystolithiasis. Cochrane Database of Systematic Reviews 2006, Issue 4. [DOI: 10.1002/14651858.CD006231]

\section{Kozarek 1992}

Kozarek RA, Ball TJ, Patterson DJ. Metallic self-expanding stent application in the upper gastrointestinal tract: caveats and concerns. Gastrointestinal Endoscopy 1992;38:1-6.

\section{Lee 2015}

Lee H, Min BH, Lee J, Shin C, Kim Y, Chung H, et al. Covered metallic stents with an anti-migration design vs. Uncovered stents for the palliation of malignant gastric outlet obstruction: a multicentre, randomised trial. American Journal of Gastroenterology 2015;110(10):1440-9.

\section{Lillemoe 1999}

Lillemoe KD, Cemeron JL, Hardacre JM, Sohn TA, Sauter PK, Coleman J, et al. Is prophylactic gastrojejunostomy indicated for unresectable periampullary cancer?. Annuals of Surgery 1999;2230:322-8.

\section{Lopera 2004}

Lopera JE, Brazzini A, Gonzales A, Castaneda-Zuniga WR. Gastroduodenal stent placement: current status. Radiographics 2004;24:1561-73.

\section{Ly 2010}

Ly J, O'Grady G, Mittal A, Plank L, Windsor J. A systematic review of methods to palliate malignant gastric outlet obstruction. Surgical Endoscopy 2010;24:290-7.

\section{Minata 2016}

Minata M, Bernardo W, de Paula Rocha R, Morita F. Stents and surgical interventions in the palliation of gastric outlet obstruction: a systematic review. Endoscopy International Open 2016;4:E1158-70.

\section{Miyasaka 2017}

Miyasaka Y, Mori Y, Nakata K, Ohtsuka T, Nakaamura M. Prophylactic biliary and gastrointestinal bypass for unresectable pancreatic head cancer: a retrospective case series. JOP 2017;18(6):470-4.

\section{Nagaraja 2014}

Nagaraja V, Eslick G, Cox M. Endoscopic stenting versus operative gastrojejunostomy for malignant gastric outlet obstruction-a systematic review and meta-analysis of randomized and non-randomized trials. Journal of Gastrointestinal Oncology 2014;5(2):92-8.

\section{Navarra 2006}

Navarra G, Musolino C, Venneri A, De Marco ML, Bartolotta M. Palliative antecolic isoperistaltic gastrojejunostomy: a randomized controlled trial comparing open and laparoscopic approaches. Surgical Endoscopy 2006;20(12):1831-4.

\section{Pach 2008}

Pach R, Orzel-Nowak A, Scully T. Ludwik Rydygier - contributor to modern surgery. Gastric Cancer 2008;11(4):187-91.

\section{Pan 2014}

Pan Y, Pan J, Guo L, Qiu M, Zhang J. Covered versus uncovered self-expandable metallic stents for palliation of malignant gastric outlet obstruction: a systematic review and metaanalysis. BMC Gastroenterology 2014;14(170):1-8.

\section{Reza 2006}

Reza MM, Blasco JA, Andradas E, Cantero R, Mayol J. Systematic review of laparoscopic versus open surgery for colorectal cancer. British Journal of Surgery 2006;93(8):921-8.

\section{Robinson 1960}

Robinson JO. The history of gastric surgery. Postgraduate Medical Journal 1960;36:706-13.

\section{Shone 1995}

Shone DN, Nikoomanesh P, Smith-Meek MM, Bender JS. Malignancy is the most common cause of gastric outlet obstruction in the era of $\mathrm{H} 2$ blockers. American Journal of Gastroenterology 1995;90(10):1769-70.

\section{Siddiqui 2007}

Siddiqui A, Spechler SJ, Huerta S. Surgical bypass versus endoscopic stenting for malignant gastroduodenal obstruction: a decision analysis. Digestive Diseases and Sciences 2007;52(1):276-81.

\section{Talseth 2014}

Talseth A, Lydersen S, Skjedlestad F, Hveem K, Edna TH. Trends in cholecystectomy rates in a defined population during and after the period of transition from open to laparoscopic surgery. Scandinavian Journal of Gastroenterology 2014;49(1):92-8.

\section{Tendler 2002}

Tendler DA. Malignant gastric outlet obstruction: bridging another divide. American Journal of Gastroenterology 2002;97(1):4.

\section{Walsh 2009}

Walsh CA, Walsh SR, Tang TY, Slack M. Total abdominal hysterectomy versus total laparoscopic hysterectomy for benign disease: a meta-analysis. European Journal of Obstetrics, Gynecology, and Reproductive Biology 2009;144(1):3-7. 


\section{Watanapa 1992}

Watanapa P, Williamson RC. Surgical palliation for pancreatic cancer: developments during the past two decades. British Journal of Surgery 1992;79:8-20.

\section{Zheng 2012}

Zheng B, Wang X, Ma B, Tian J, Jiang L, Yang K. Endoscopic stenting versus gastrojejunostomy for palliation of malignant gastric outlet obstruction. Digestive Endoscopy 2012;24:71-8.

CHARACTERISTICS OF STUDIES

Characteristics of included studies [ordered by study ID]

Fiori 2013

\begin{tabular}{ll}
\hline Methods & Single-centre randomised controlled study \\
\hline Participants & 18 people with advanced adenocarcinoma of the antropyloric region and symptoms of GOO \\
& Men: $13 / 18(72 \%)$ \\
& Mean age: 71 years \\
\hline Interventions & people randomised to gastrojejunostomy. \\
& Further details: standard xiphoumbilical laparotomy. The gastroenteric anastomosis was on the poste- \\
rior wall of the stomach. & 9 people randomised to duodenal stenting. \\
& $\begin{array}{l}\text { Further details: in all } 9 \text { people, covered self-expanding metal stent (Ultraflex Covered Stent System, } \\
\text { Boston Scientific Corporation) measuring } 10-15 \text { cm in length were inserted at the level of the stenosis } \\
\text { and position checked with fluoroscopic and endoscopic control. } \\
\text { No information regarding biliary obstruction included. As all participants had unresectable primary } \\
\text { antropyloric adenocarcinoma, the risk of biliary obstruction was significantly reduced and, hence, may } \\
\text { not have occurred in any of the included participants. }\end{array}$
\end{tabular}

\section{References to other published versions of this review}

Upchurch E, Cirocchi R, Ragusa M. Stent placement versus surgical palliation for malignant gastric outlet obstruction. Cochrane Database of Systematic Reviews 2017, Issue 1. [DOI: 10.1002/14651858.CD012506]

* Indicates the major publication for the study Upchurch 2017

\footnotetext{
Outcomes

- Gastric emptying (assessed by clinical evaluation of symptoms and upper gastrointestinal contrast radiography)

- Postprocedural mortality and morbidity

- Time to resumption of oral feeding following the procedure

- Length of hospital stay postprocedure

- Complications during follow-up period

- Crude survival

- Satisfaction of participants and their family members with regard to the procedure
}

Notes

Included participants had stage IV cancer with distant metastases and no evidence of an indication for palliative gastric resection (i.e. significant bleeding or perforation)

\section{Risk of bias}

\begin{tabular}{lll}
\hline Bias & Authors' judgement & Support for judgement \\
\hline $\begin{array}{l}\text { Random sequence genera- } \\
\text { tion (selection bias) }\end{array}$ & Low risk & $\begin{array}{l}\text { Quote: "Selected patients were assigned to } 1 \text { of the } 2 \text { forms of treatment ac- } \\
\text { cording to tables of random numbers." }\end{array}$ \\
\hline
\end{tabular}


Fiori 2013 (Continued)

$\begin{array}{ll}\begin{array}{l}\text { Allocation concealment } \\ \text { (selection bias) }\end{array} & \text { Quw risk } \\ & \begin{array}{l}\text { Quote: "Randomization was performed by a physician unaware of the clinical } \\ \text { form the procedures." }\end{array}\end{array}$

\begin{tabular}{|c|c|c|}
\hline $\begin{array}{l}\text { Blinding of participants } \\
\text { and personnel (perfor- }\end{array}$ & High risk & $\begin{array}{l}\text { Comment: participants would have been aware of the intervention they re- } \\
\text { ceived. }\end{array}$ \\
\hline
\end{tabular}
mance bias)

All outcomes

Blinding of outcome as- High risk sessment (detection bias) All outcomes
Quote: "Patients were followed up every 3 months until death by the surgeons who performed the procedure."

Comment: the surgeon would have knowledge of the intervention received. All procedures were performed by surgeons who also had a special intervention in interventional endoscopy which could, however, overcome any possible bias related to preference of 1 form of treatment.

\begin{tabular}{lll}
\hline $\begin{array}{l}\text { Incomplete outcome data } \\
\text { (attrition bias) } \\
\text { All outcomes }\end{array}$ & Low risk & Quote: "No patient was lost to follow up." \\
\hline $\begin{array}{l}\text { Selective reporting (re- } \\
\text { porting bias) }\end{array}$ & Low risk & Comment: all important outcomes reported \\
\hline Other bias & Unclear risk & $\begin{array}{l}\text { Comment: the proportion of men was higher in the gastroenterostomy group } \\
(78 \%) \text { compared to the duodenal stent group (66\%). }\end{array}$ \\
\hline
\end{tabular}

Jeurnick 2010

\begin{tabular}{|c|c|}
\hline Methods & Multi-centre, randomised controlled study \\
\hline \multirow[t]{5}{*}{ Participants } & $\begin{array}{l}77 \text { participants with GOO were eligible to be included; however, } 38 \text { participants refused to participate } \\
\text { as they preferred stent placement over surgical procedure. }\end{array}$ \\
\hline & 39 participants from 11 centres were randomised and included. \\
\hline & $\begin{array}{l}\text { Primary site of malignancy: pancreatic }(72 \%) \text {, duodenum }(10 \%) \text {, cholangiocarcinoma }(2.5 \%) \text {, gastric } \\
(8 \%) \text {, papilla }(2.5 \%) \text { and metastatic disease }(5 \%)\end{array}$ \\
\hline & Men: $20 / 39(51 \%)$ \\
\hline & Mean age: 66 years \\
\hline \multirow[t]{5}{*}{ Interventions } & $\begin{array}{l}18 \text { participants randomised to gastrojejunostomy. } 17 \text { participants underwent the procedure. The pro- } \\
\text { cedure failed in } 1 \text { participant due to extensive peritoneal metastases. }\end{array}$ \\
\hline & $\begin{array}{l}\text { Further details: participants underwent an open (16 participants) or laparoscopic ( } 2 \text { participants) gas- } \\
\text { trojejunostomy, either antecolic or retrocolic }\end{array}$ \\
\hline & 21 participants randomised to duodenal stenting. 20 participants received the intervention. \\
\hline & $\begin{array}{l}\text { Further details: participants received an Enteral Wallflex stent (Boston Scientific, Natick, MA, USA) } \\
\text { with a diameter of } 22 \mathrm{~mm} \text { and a length of } 60 \mathrm{~mm}, 90 \mathrm{~mm} \text { or } 120 \mathrm{~mm} \text {. The stent was introduced over a } \\
\text { guidewire and deployed under endoscopic and fluoroscopic monitoring. }\end{array}$ \\
\hline & $\begin{array}{l}14 \text { participants }(78 \%) \text { randomised to gastrojejunostomy were also treated for jaundice ( } 12 \text { underwent } \\
\text { endoscopic biliary drainage ( } 10 \text { preoperatively and } 2 \text { postoperatively) and } 2 \text { underwent a choledocho- } \\
\text { jejunostomy during the gastrojejunostomy procedure. }\end{array}$ \\
\hline
\end{tabular}


Jeurnick 2010 (Continued)

16 participants (76\%) randomised to duodenal stenting were also treated for jaundice by endoscopic biliary drainage (10 pre-, 2 peri- and 4 post-) duodenal stent placement

\begin{tabular}{|c|c|c|}
\hline Outcomes & \multicolumn{2}{|c|}{$\begin{array}{l}\text { - Medical effects (complications, hospital stay and survival) } \\
\text { - Quality of life (assessed using standardised quality of life questionnaires) } \\
\text { - Costs } \\
\text { Data analysed by intention to treat }\end{array}$} \\
\hline Notes & \multicolumn{2}{|c|}{$\begin{array}{l}\text { All included participants had unresectable or metastatic disease with a Gastric Outlet Obstruction } \\
\text { Scoring System score of } 0 \text { (no oral intake) or } 1 \text { (liquid intake only). Excluded participants who had pre- } \\
\text { vious gastric, periampullary or duodenal surgery, or previous palliative treatment for this condition. }\end{array}$} \\
\hline \multicolumn{3}{|l|}{ Risk of bias } \\
\hline Bias & Authors' judgement & Support for judgement \\
\hline $\begin{array}{l}\text { Random sequence genera- } \\
\text { tion (selection bias) }\end{array}$ & Low risk & $\begin{array}{l}\text { Quote: "Randomization was performed centrally at the Erasmus MC Rotter- } \\
\text { dam by using computer generated lists. Patients were stratified by centre and } \\
\text { previous treatment of obstructive jaundice." }\end{array}$ \\
\hline $\begin{array}{l}\text { Allocation concealment } \\
\text { (selection bias) }\end{array}$ & Low risk & $\begin{array}{l}\text { Quote: "Randomization was performed centrally at the Erasmus MC Rotter- } \\
\text { dam by using computer generated lists. Patients were stratified by centre and } \\
\text { previous treatment of obstructive jaundice." }\end{array}$ \\
\hline $\begin{array}{l}\text { Blinding of participants } \\
\text { and personnel (perfor- } \\
\text { mance bias) } \\
\text { All outcomes }\end{array}$ & High risk & $\begin{array}{l}\text { Comment: participants would have been aware of the intervention they re- } \\
\text { ceived. }\end{array}$ \\
\hline $\begin{array}{l}\text { Blinding of outcome as- } \\
\text { sessment (detection bias) } \\
\text { All outcomes }\end{array}$ & Unclear risk & $\begin{array}{l}\text { Comment: despite the use of standardised case record forms, it was unclear } \\
\text { whether the specially trained research nurses who undertook follow-up home } \\
\text { visits were aware of the intervention that the participant had received. }\end{array}$ \\
\hline $\begin{array}{l}\text { Incomplete outcome data } \\
\text { (attrition bias) } \\
\text { All outcomes }\end{array}$ & Low risk & $\begin{array}{l}\text { Comment: all participants allocated to each arm were analysed as exemplified } \\
\text { in the study profile. }\end{array}$ \\
\hline $\begin{array}{l}\text { Selective reporting (re- } \\
\text { porting bias) }\end{array}$ & Low risk & Comment: all important outcomes were reported. \\
\hline Other bias & Low risk & $\begin{array}{l}\text { Comment: participants were well matched for age, sex and location of prima- } \\
\text { ry malignancy. A higher proportion of participants randomised to duodenal } \\
\text { stenting had unresectable disease ( } 76 \% \text { compared to } 59 \%) \text {, whereas, a higher } \\
\text { proportion in the gastrojejunostomy group had a poor medical condition ( } 12 \% \\
\text { compared to } 0 \%) \text {. }\end{array}$ \\
\hline
\end{tabular}

Mehta 2006

\begin{tabular}{ll}
\hline Methods & Single-centre randomised controlled study \\
\hline Participants & 27 participants with malignant GOO and unresectable or advanced metastatic malignancy (or both) \\
who were fit for intervention. \\
Primary site of malignancy: pancreatic (56\%), gastric (15\%), cholangiocarcinoma (7\%), gallbladder \\
$\begin{array}{l}\text { (3.5\%) and metastatic disease (15\%). 1 participant (3.5\%) was subsequently found to have a benign } \\
\text { gastric ulcer, as opposed to an underlying malignancy, as the cause of the GOO. }\end{array}$ \\
\hline
\end{tabular}


Mehta 2006 (Continued)

\section{Men: $13 / 27(48 \%)$}

Mean age: 68.9 years

Interventions

14 participants randomised to gastrojejunostomy. 13 participants underwent the procedure (1 participant died prior to the intervention).

Further details: laparoscopic, antecolic gastrojejunostomy with stapled gastrojejunal anastomosis. The 2 surgeons involved in the study had undertaken laparoscopic gastrojejunostomy for 10 years and had completed over 50 cases prior to the study.

13 participants randomised to duodenal stenting. Stents were unable to be passed in 2 participants and they went on to have a gastrojejunostomy.

Further details: enteral Wallstent (Boston Scientific, Natick, MA, USA) inserted either orally (8 participants) or via a percutaneous gastrostomy tract ( 3 participants). The radiology team had performed 21 duodenal stents prior to the study.

6 participants in the gastrojejunostomy group and 7 participants in the duodenal stenting group also underwent biliary decompression by either endoscopic retrograde cholangiopancreatography or percutaneous transhepatic cholangiography prior to the operation.

\begin{tabular}{ll}
\hline Outcomes & - Postprocedural complications \\
- & Duration of hospital stay postintervention \\
- SF-36 scores (postintervention versus 1 month) \\
- Data analysed by intention to treat
\end{tabular}

Notes All participants in the study presented with typical symptoms of nausea, vomiting and abdominal pain, with confirmation of diagnosis by gastroscopy, contrast swallow or computerised tomography.

\section{Risk of bias}

\begin{tabular}{|c|c|c|}
\hline Bias & Authors' judgement & Support for judgement \\
\hline $\begin{array}{l}\text { Random sequence genera- } \\
\text { tion (selection bias) }\end{array}$ & Low risk & $\begin{array}{l}\text { Quote: "Randomization was performed using a computer-generated list con- } \\
\text { cealed from the investigators at the time of enrolment." }\end{array}$ \\
\hline $\begin{array}{l}\text { Allocation concealment } \\
\text { (selection bias) }\end{array}$ & Low risk & $\begin{array}{l}\text { Quote: "Randomization was performed using a computer-generated list con- } \\
\text { cealed from the investigators at the time of enrolment." }\end{array}$ \\
\hline $\begin{array}{l}\text { Blinding of participants } \\
\text { and personnel (perfor- } \\
\text { mance bias) } \\
\text { All outcomes }\end{array}$ & High risk & $\begin{array}{l}\text { Comment: participants consented to both treatment options prior to alloca- } \\
\text { tion, but would have been aware of the intervention they received. }\end{array}$ \\
\hline $\begin{array}{l}\text { Blinding of outcome as- } \\
\text { sessment (detection bias) } \\
\text { All outcomes }\end{array}$ & Unclear risk & Comment: information not available \\
\hline $\begin{array}{l}\text { Incomplete outcome data } \\
\text { (attrition bias) } \\
\text { All outcomes }\end{array}$ & High risk & $\begin{array}{l}\text { Quote: "6 patients in the laparoscopic gastrojejunostomy group and } 7 \text { patients } \\
\text { in the duodenal stenting group completed questionnaires at } 1 \text { month." } \\
\text { Comment: therefore, } 7 \text { participants did not complete questionnaires at } 1 \\
\text { month and the reasons were not documented. }\end{array}$ \\
\hline $\begin{array}{l}\text { Selective reporting (re- } \\
\text { porting bias) }\end{array}$ & Low risk & Comment: all important outcomes reported \\
\hline
\end{tabular}


Mehta 2006 (Continued)
Other bias
Low risk
Comment: no other source of bias identified. Participants were well matched for age, sex and weight. Unclear how well matched the 2 groups were for site of primary malignancy

GOO: gastric outlet obstruction; SF-36: 36-item Short Form Health Survey.

Characteristics of excluded studies [ordered by study ID]

\begin{tabular}{|c|c|}
\hline Study & Reason for exclusion \\
\hline Abdellah-Fernandez 2015 & Retrospective study \\
\hline Alonso-Larraga 2012 & Retrospective study \\
\hline Arigami 2016 & Retrospective study \\
\hline Bukhari 2016 & Alternative treatment: endoscopic ultrasound-guided gastrojejunostomy \\
\hline Chandrasegaram 2012 & Retrospective study \\
\hline Del Piano 2005 & Retrospective study \\
\hline El-Shabrawi 2013 & Retrospective study \\
\hline Espinel 2006 & Non-randomised controlled trial \\
\hline Fiori 2016 & Non-randomised controlled trial \\
\hline Jang 2017 & Retrospective study \\
\hline Jeurnick 2007a & Retrospective study \\
\hline Johnsson 2004 & Non-randomised controlled trial \\
\hline Keranen 2013 & Retrospective study \\
\hline Khashab 2013 & Retrospective study \\
\hline Kimura 2013 & Retrospective study \\
\hline Kubota 2007 & Retrospective study \\
\hline Kumagai 2016 & Alternative treatment: stomach partitioning \\
\hline Maetani 2004 & Retrospective study \\
\hline Maetani 2005 & Retrospective study \\
\hline Mejia 2006 & Retrospective study \\
\hline Mittal 2004 & Retrospective study \\
\hline No 2013 & Retrospective study \\
\hline
\end{tabular}




\begin{tabular}{|c|c|}
\hline Study & Reason for exclusion \\
\hline Park 2015 & Retrospective study \\
\hline Perez-Miranda 2016 & Alternative treatment: endoscopic ultrasound-guided gastrojejunostomy \\
\hline Rudolph 2011 & Retrospective study \\
\hline Schmidt 2009 & Non-randomised controlled trial \\
\hline Shimazaki 2013 & Non-randomised controlled trial \\
\hline Taniguchi 2014 & Non-randomised controlled trial \\
\hline Tsauo 2016 & Retrospective study \\
\hline Tsuchida 2013 & Non-randomised controlled trial \\
\hline Uemura 2018 & Retrospective study \\
\hline Van Hooft 2009 & Non-randomised controlled trial \\
\hline Wong 2002 & Retrospective study \\
\hline Yim 2001 & Retrospective study \\
\hline Yoshida 2017 & Retrospective study \\
\hline Yukimoto 2018 & Retrospective study \\
\hline
\end{tabular}

\section{DATA AND ANALYSES}

\section{Comparison 1. Surgical palliation versus duodenal stenting}

\begin{tabular}{|c|c|c|c|c|}
\hline Outcome or subgroup title & No. of studies & $\begin{array}{l}\text { No. of partici- } \\
\text { pants }\end{array}$ & Statistical method & Effect size \\
\hline $\begin{array}{l}1 \text { Re-establishment of oral intake } \\
\text { (technical success of the interven- } \\
\text { tion) }\end{array}$ & 3 & 82 & $\begin{array}{l}\text { Risk Ratio (M-H, Random, 95\% } \\
\mathrm{Cl} \text { ) }\end{array}$ & $0.98[0.88,1.09]$ \\
\hline $\begin{array}{l}2 \text { Time to re-establishment of oral } \\
\text { intake (days) }\end{array}$ & 2 & 57 & $\begin{array}{l}\text { Mean Difference (IV, Random, } \\
95 \% \mathrm{CI})\end{array}$ & $-3.07[-4.76,-1.39]$ \\
\hline 3 All-cause mortality & 1 & & $\begin{array}{l}\text { Risk Ratio (M-H, Random, 95\% } \\
\mathrm{Cl})\end{array}$ & Subtotals only \\
\hline $\begin{array}{l}4 \text { Median survival postintervention } \\
\text { (days) }\end{array}$ & 1 & & $\begin{array}{l}\text { Mean Difference (IV, Random, } \\
95 \% \mathrm{CI})\end{array}$ & Subtotals only \\
\hline $\begin{array}{l}5 \text { Time to recurrence of obstructive } \\
\text { symptoms }\end{array}$ & 2 & 57 & $\begin{array}{l}\text { Risk Ratio (M-H, Random, 95\% } \\
\mathrm{Cl} \text { ) }\end{array}$ & $5.08[0.96,26.74]$ \\
\hline
\end{tabular}




\begin{tabular}{|c|c|c|c|c|}
\hline Outcome or subgroup title & No. of studies & $\begin{array}{l}\text { No. of partici- } \\
\text { pants }\end{array}$ & Statistical method & Effect size \\
\hline 6 Serious adverse events & 3 & 84 & $\begin{array}{l}\text { Risk Ratio (M-H, Random, 95\% } \\
\text { Cl) }\end{array}$ & $1.15[0.33,3.98]$ \\
\hline $\begin{array}{l}7 \text { Serious adverse events: need for } \\
\text { reintervention }\end{array}$ & 3 & 84 & $\begin{array}{l}\text { Risk Ratio (M-H, Random, 95\% } \\
\text { Cl) }\end{array}$ & $4.71[1.36,16.30]$ \\
\hline 8 Minor adverse events & 3 & 84 & $\begin{array}{l}\text { Risk Ratio (M-H, Random, 95\% } \\
\text { Cl) }\end{array}$ & $0.35[0.07,1.61]$ \\
\hline 9 Length of hospital stay (days) & 3 & 84 & $\begin{array}{l}\text { Mean Difference (IV, Random, } \\
95 \% \mathrm{CI} \text { ) }\end{array}$ & $-6.70[-9.41,-3.98]$ \\
\hline
\end{tabular}

Analysis 1.1. Comparison 1 Surgical palliation versus duodenal stenting, Outcome 1 Re-establishment of oral intake (technical success of the intervention).

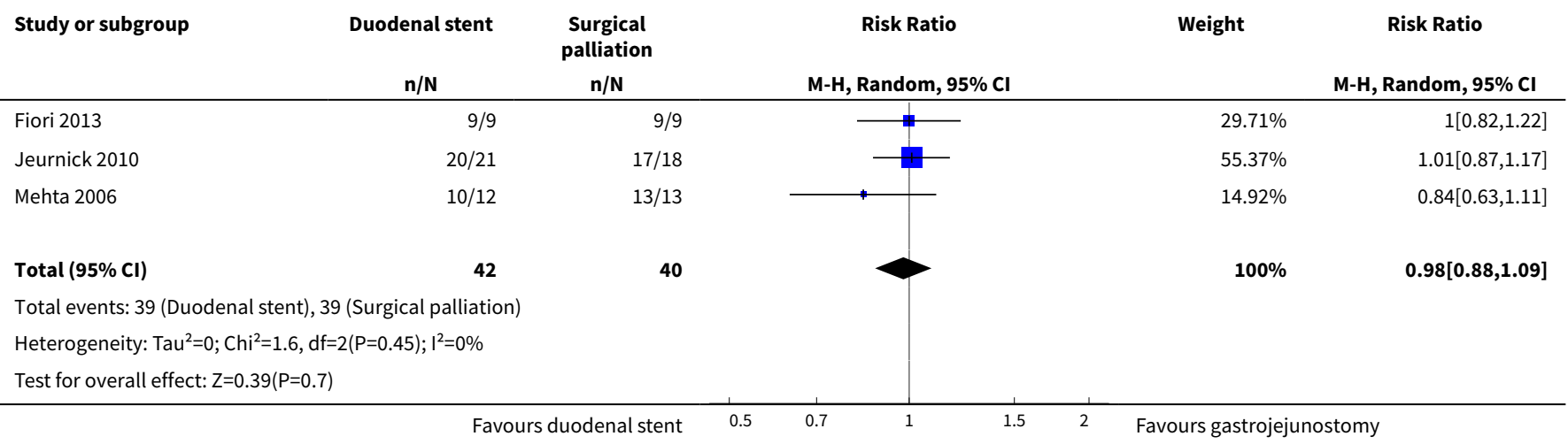

Analysis 1.2. Comparison 1 Surgical palliation versus duodenal stenting, Outcome 2 Time to re-establishment of oral intake (days).

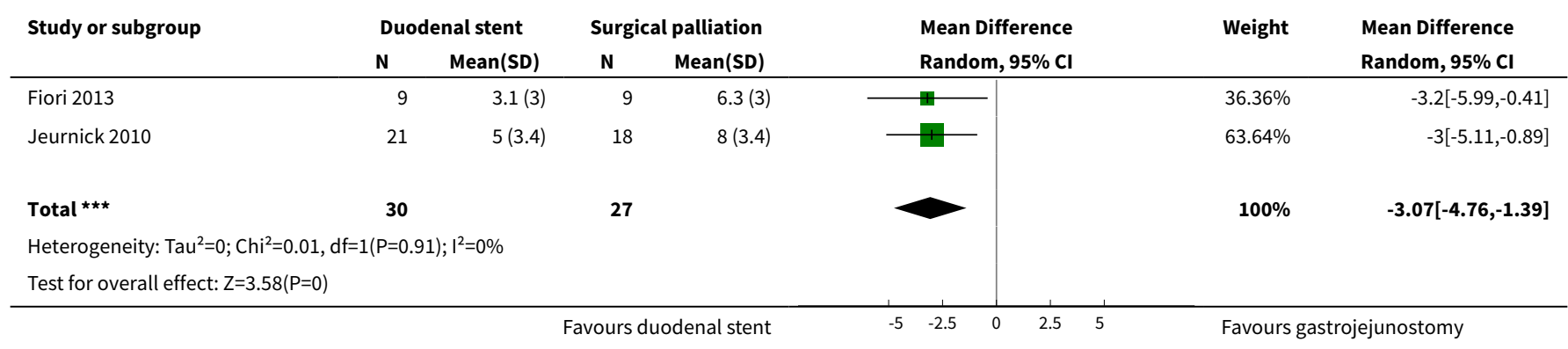


Analysis 1.3. Comparison 1 Surgical palliation versus duodenal stenting, Outcome 3 All-cause mortality.

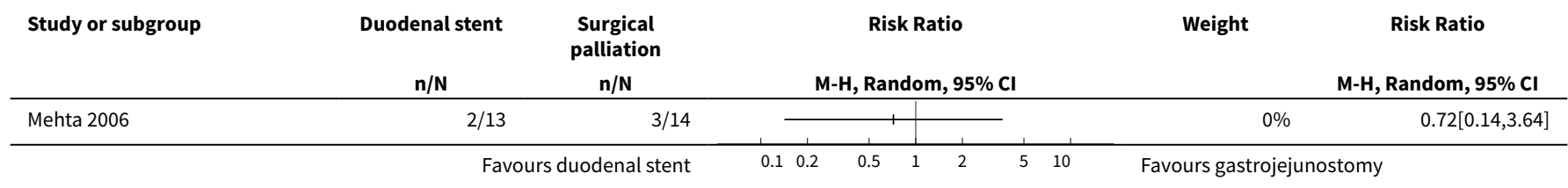

Analysis 1.4. Comparison 1 Surgical palliation versus duodenal stenting, Outcome 4 Median survival postintervention (days).

\begin{tabular}{|c|c|c|c|c|c|c|c|c|c|c|}
\hline \multirow[t]{2}{*}{ Study or subgroup } & \multicolumn{2}{|c|}{ Duodenal stent } & \multicolumn{2}{|c|}{ Surgical palliation } & \multirow{2}{*}{\multicolumn{3}{|c|}{$\begin{array}{l}\text { Mean Difference } \\
\text { Random, } 95 \% \mathrm{CI}\end{array}$}} & & \multirow[t]{2}{*}{ Weight } & \multirow{2}{*}{$\begin{array}{l}\text { Mean Difference } \\
\text { Random, } 95 \% \mathrm{Cl}\end{array}$} \\
\hline & $\mathbf{N}$ & Mean(SD) & $\mathbf{N}$ & $\operatorname{Mean}(\mathrm{SD})$ & & & & & & \\
\hline Jeurnick 2010 & 21 & $56(50)$ & 18 & $78(50)$ & & 1 & - & & $0 \%$ & $-22[-53.45,9.45]$ \\
\hline & & & urs & lenal stent & -50 & -25 & 25 & 立 & Favours g & jejunostomy \\
\hline
\end{tabular}

Analysis 1.5. Comparison 1 Surgical palliation versus duodenal stenting, Outcome 5 Time to recurrence of obstructive symptoms.

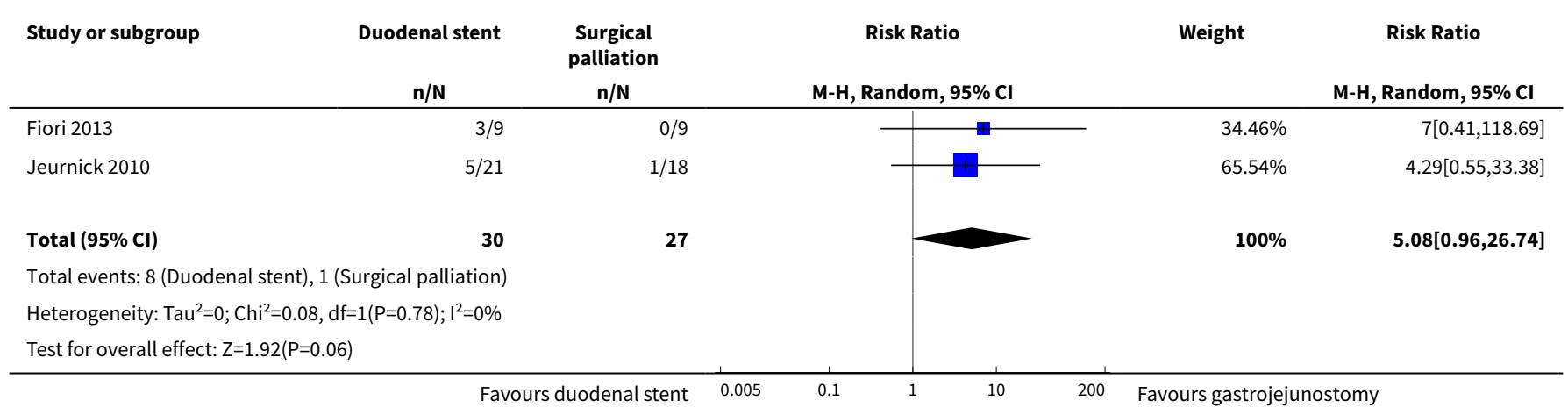

Analysis 1.6. Comparison 1 Surgical palliation versus duodenal stenting, Outcome 6 Serious adverse events.

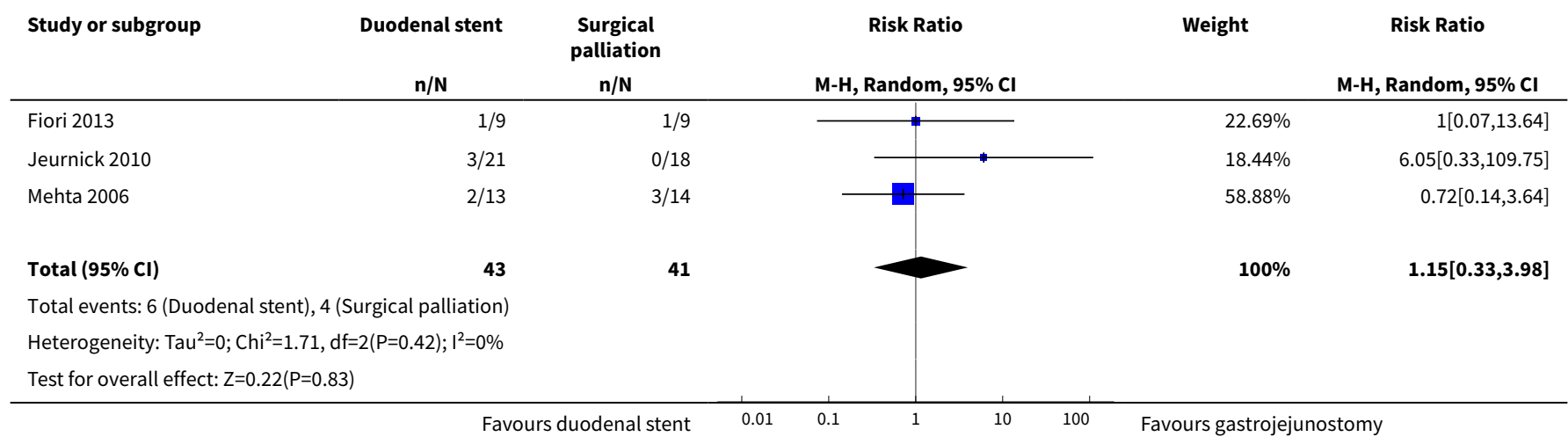


Analysis 1.7. Comparison 1 Surgical palliation versus duodenal stenting, Outcome 7 Serious adverse events: need for reintervention.

\begin{tabular}{|c|c|c|c|c|c|c|c|}
\hline \multirow[t]{2}{*}{ Study or subgroup } & \multirow{2}{*}{$\begin{array}{c}\text { Duodenal stent } \\
n / N \\
\end{array}$} & \multirow{2}{*}{$\begin{array}{c}\text { Surgical } \\
\text { palliation } \\
n / N\end{array}$} & \multicolumn{3}{|c|}{ Risk Ratio } & \multirow[t]{2}{*}{ Weight } & \multirow{2}{*}{$\begin{array}{l}\text { Risk Ratio } \\
\text { Random, 95\% Cl }\end{array}$} \\
\hline & & & & M-H, Random, 95 & & & \\
\hline Fiori 2013 & $3 / 9$ & $0 / 9$ & & $\longrightarrow$ & - & $19.24 \%$ & $7[0.41,118.69]$ \\
\hline Jeurnick 2010 & $10 / 21$ & $2 / 18$ & & & & $80.76 \%$ & $4.29[1.08,17.06]$ \\
\hline Mehta 2006 & $0 / 13$ & $0 / 14$ & & & & & Not estimable \\
\hline \multicolumn{8}{|c|}{ Total events: 13 (Duodenal stent), 2 (Surgical palliation) } \\
\hline \multicolumn{8}{|c|}{ Heterogeneity: $\mathrm{Tau}^{2}=0 ; \mathrm{Chi}^{2}=0.09, \mathrm{df}=1(\mathrm{P}=0.76) ; \mathrm{I}^{2}=0 \%$} \\
\hline Test for overall effec & & & & & & & \\
\hline
\end{tabular}

Analysis 1.8. Comparison 1 Surgical palliation versus duodenal stenting, Outcome 8 Minor adverse events.

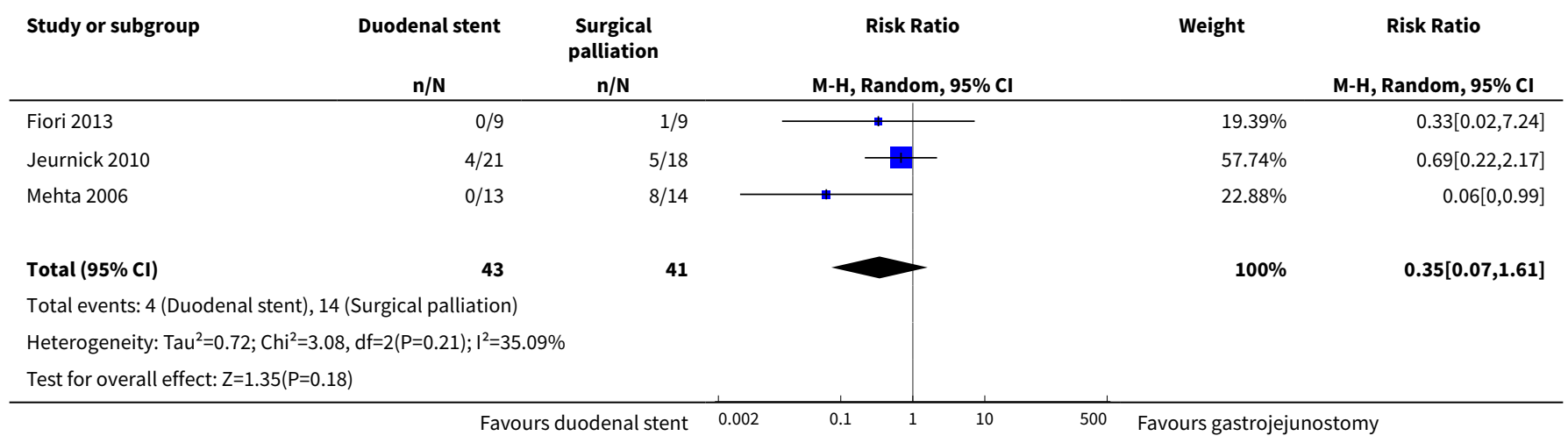

Analysis 1.9. Comparison 1 Surgical palliation versus duodenal stenting, Outcome 9 Length of hospital stay (days).

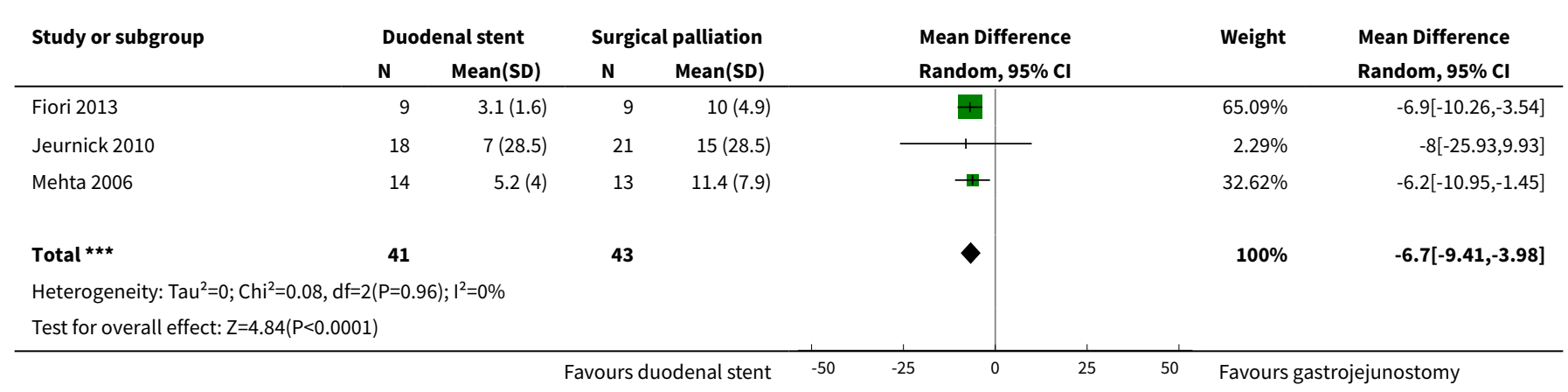




\section{AP PEN DICES}

\section{Appendix 1. Glossary of terms}

Ampullary carcinoma: a cancerous growth that occurs at the ampulla of Vater. This is the area in the small bowel where the biliary system drains into the gastrointestinal tract.

Anastomosis: a surgical connection (join) between two tubular structures. In a gastrojejunostomy, the anastomosis is between the stomach (gastric) and jejunum (small bowel).

Anastomotic leak: the breakdown in the join between two structures. This results in leakage of the contents of the structures into the abdominal cavity resulting in significant problems.

Anatomical position: the standard position of a structure when the body is in the standing position, facing forwards, and has not been altered by a disease process.

Benign: refers to conditions that are not cancerous.

Bile duct: the tubular structures that drain bile (greenish liquid that is necessary for the digestion and absorption of fat) from the liver and gallbladder to the small bowel.

Biliary obstruction: blockage of the bile ducts due to any cause, which includes cancers. This typically results in jaundice (yellowing of the skin).

Bolus: a ball-like mixture of food and saliva that forms in the mouth during the process of chewing.

Carbon dioxide: a colourless gas with a density approximately $50 \%$ higher than that of dry air. This gas is typically used in key-hole surgery to insufflate the abdominal cavity.

Cholangiocarcinoma: a cancer (malignant growth) of the bile ducts.

Comorbidities: the presence of one or more additional diseases or disorders that may affect the overall health of the person.

Conscious sedation: a technique in which the use of a drug or drugs produces a state of depression of the central nervous system, but with maintenance of verbal contact throughout.

Distal: the area that is at the bottom end. For example: the distal end of the stomach is the bottom end of the stomach.

Duodenum: the first part of the small bowel that begins after the stomach.

Electrolyte imbalance: a change in the concentration of salts in the blood (e.g. potassium, sodium), which are essential for normal cellular function. For example, this can occur after vomiting.

Epigastrium: describes the area of the body that sits below the chest in the centre. Epigastric pain refers to pain that is felt in this area.

Endoscope: the instrument used to look inside the stomach and small bowel during an endoscopy. It consists of a hollow tube, about the size of your fifth finger, with a light and camera. Instruments can be passed down the tube to take tissue samples from the stomach and small bowel.

Endoscopy: the process of looking inside the body with a camera attached to a scope. In gastroscopy, the camera is inserted via the mouth to the stomach and small bowel.

Fluoroscopic: relates to the radiological technique that uses specialised dye and x-ray. It is typically used to monitor the placement of devices, including stents, in the body as it allows exact placement to be monitored.

Gastric: refers to the stomach.

Gastric outlet: the area of the stomach through which food passes on its route to the small bowel. The gastric outlet is in the part of the stomach that is known as the pylorus.

Gastric outlet obstruction (GOO): describes the obstruction to the passage of food and liquid at the distal end of the stomach, also known as the gastric outlet.

Gastrojejunostomy: describes a connection between the stomach (gastric) and small bowel (jejunum).

Helicobacter pylori: this is the name given to the bacteria that has been shown to be associated with peptic ulcer disease. 
Intraluminal: refers to the inside of a hollow structure.

Jaundice: the yellow discolouration of the skin that can occur as a result of reduced drainage of bile (or biliary obstruction).

Jejunum: the middle part of the small bowel that is distal to the duodenum.

Laparoscopic: this is also referred to as minimal access or key hole surgery. This is surgery via small incisions on the abdomen through which specialised instruments are passed. This alleviates the need for large incisions on the abdomen.

Lateral: a term used to describe the position of a structure or object. Lateral describes objects or structures to the side, whereas, medial describes objects or structure lying along the middle or centre.

Lymphoma: a cancer that affects the lymph nodes of the body.

Malignant: refers to a cancerous process.

Metastatic disease: a disease that has spread from the organ that it originates from to lymph nodes or other organs around the body. Metastatic disease typically refers to an advanced stage of cancer.

Migration: the movement from the original position to another position. In stent migration refers to movement of the stent from the position it was placed to a different, and typically worse, position.

Morbidity: complications or events that impact on the persons' ability to function and return to their normal level of functioning. For example, a chest infection that prevents walking is said to have caused morbidity.

Mortality: death rate.

Occlusion: blockage. This can be partial or complete.

Palliation: the control of symptoms without the treatment of, or attempt to treat, the underlying cause of the symptoms.

Pathological: the result of the underlying disease process.

Peptic ulcer: a break or erosion in the lining of the stomach or small bowel.

Perforation: a small hole that appears in part of the gastrointestinal tract as a cause of disease or an intervention. For example, a gastric perforation is a hole in the stomach from which stomach contents can escape into the rest of the abdominal cavity.

Perioperative: at the time of operation. For example; a perioperative complication would be something that occurs during the operation.

Physiological reserve: refers to the capacity, predominantly in terms of heart and lung function, that a person has to withstand various insults to the body.

Pneumoperitoneum: in laparoscopic surgery, carbon dioxide is placed inside the abdomen to create space. This is known as a pneumoperitoneum.

Port: a port is a specialised device used in laparoscopic surgery through which the specialised instruments are passed. A port is either 5 $\mathrm{mm}$ or $12 \mathrm{~mm}$ in size and, thus, the incisions are approximately this size.

Postprandial: occurs following eating.

Proton-pump Inhibitor (PPI): a medicine that reduces the production of acid in the stomach. This helps to treat ulcers in the stomach.

Pylorus: the name given to the distal end of the stomach where the gastric outlet sits. A pyloric carcinoma is a cancer that grows at the pylorus.

Roux-en-y anastomosis: this describes a surgically created end-to-side anastomosis, usually between the stomach and small bowel.

Self-expanding metal stent (SEMS): a stent that expands to fit the person depending on the space and external forces encountered.

Stent: a hollow tube, either plastic or metal, or self-expanding, which is used to keep a passageway within the body open.

Terminal: refers to conditions for which there is no cure and for which this will be the cause of death. This does not mean that the symptoms cannot be treated or improved.

Umbilicus: the area at the belly-button or navel. 


\section{Appendix 2. CENTRAL search strategy}

1. exp Gastric Outlet Obstruction/

2. ((gastric or gastro* or stomach or pyloric) adj5 (obstruction ${ }^{\star}$ or obstructed or stenosis or stenoses or stricture* or narrow*)).tw,kw.

3. "GOO".tw,kw.

4. or/1-3

5. $\exp$ Stents/

6. stent ${ }^{\star} \cdot \mathrm{mp}$.

7. (SEMT or SEMTs).tw,kw.

8. exp Palliative Care/

9. (palliative or palliation).tw,kw.

10.or/5-9

11.4 and 10

\section{Appendix 3. MEDLINE Ovid search strategy}

1. exp Gastric Outlet Obstruction/

2. ((gastric or gastro* or stomach or pyloric) adj5 (obstruction* or obstructed or stenosis or stenoses or stricture* or narrow*)).tw,kw.

3. "GOO".tw,kw.

4. or/1-3

5. $\exp$ Stents/

6. stent ${ }^{\star} . \mathrm{mp}$.

7. (SEMT or SEMTs).tw,kw.

8. exp Palliative Care/

9. (palliative or palliation).tw,kw.

10.or/5-9

11.4 and 10

12. randomized controlled trial.pt.

13.controlled clinical trial.pt.

14.random*.ab.

15. placebo.ab.

16.trial.ab.

17.groups.ab.

18.or/12-17

19.exp animals/ not humans.sh.

20.18 not 19

21.11 and 20

\section{Appendix 4. Embase Ovid search strategy}

1. exp stomach obstruction/

2. ((gastric or gastro* or stomach or pyloric) adj5 (obstruction* or obstructed or stenosis or stenoses or stricture* or narrow $\left.{ }^{\star}\right)$ ).tw,kw.

3. "GOO".tw,kw.

4. or/1-3

5. exp stent/

6. stent ${ }^{\star} \cdot \mathrm{mp}$.

7. (SEMT or SEMTs).tw,kw.

8. exp palliative therapy/

9. (palliative or palliation).tw,kw.

10.or/5-9

11.4 and 10

12.(random: or placebo: or double-blind:).mp.

13.clinical trial:.mp.

14.blind:.tw.

15.or/12-14 
16.exp animal/ not human/

17.15 not 16

18.11 and 17

\section{CONTRIBUTIONS OF AUTHORS}

Conceiving the review: EU.

Designing the review: EU.

Co-ordinating the review: EU.

Designing search strategies and analysing the results: EU, RC.

Writing the review: EU.

Assessing the review: RC, MR.

\section{DECLARATIONS OF INTEREST}

This report is independent research funded by the National Institute for Health Research (NIHR Cochrane Programme Grants, 13/89/03 - Evidence-based diagnosis and management of upper digestive, hepatobiliary and pancreatic disorders). The views expressed in this publication are those of the authors and not necessarily those of the National Health Service, the NIHR or the Department of Health.

EU: none known.

MR: none known.

RC: none known.

\section{SOURCES OF SUPPORT}

\section{Internal sources}

- Gloucestershire Hospitals NHS Foundation Trust, UK.

\section{External sources}

- No sources of support supplied

\section{DIFFERENCES BETWEEN PROTOCOLANDREVIEW}

We included additional outcome measures of median survival, minor adverse events and need for reintervention.

We measure technical success as not all studies included time to resumption of oral intake. Therefore, this was used as an additional measure to compare the two methods.

It became clear that the three studies utilised different definitions for adverse events and, thus, we included minor as well as the planned serious adverse events to ensure all negative outcomes were recorded.

We added the need for reintervention as an additional secondary outcome as this was not always included as an adverse event. Further interventions would add additional risks and would impact the quality of life of the participants. The outcome of 'time to recurrence of obstructive symptoms' was not reported, but rather the presence or absence of recurrence symptoms.

\section{INDEX TERMS}

\section{Medical Subject Headings (MeSH)}

*Duodenum; *Stents [statistics \& numerical data]; Eating; Gastric Outlet Obstruction [etiology] [mortality] [*surgery]; Gastrointestinal Neoplasms [ ${ }^{\star}$ complications]; Length of Stay; Palliative Care [*methods]; Randomized Controlled Trials as Topic; Recurrence; Time Factors

\section{MeSH check words}

Adult; Humans 